\title{
تبليات أدب الرعب في رواية فرانكشتاين في بغداد أحمد سعداوي
}
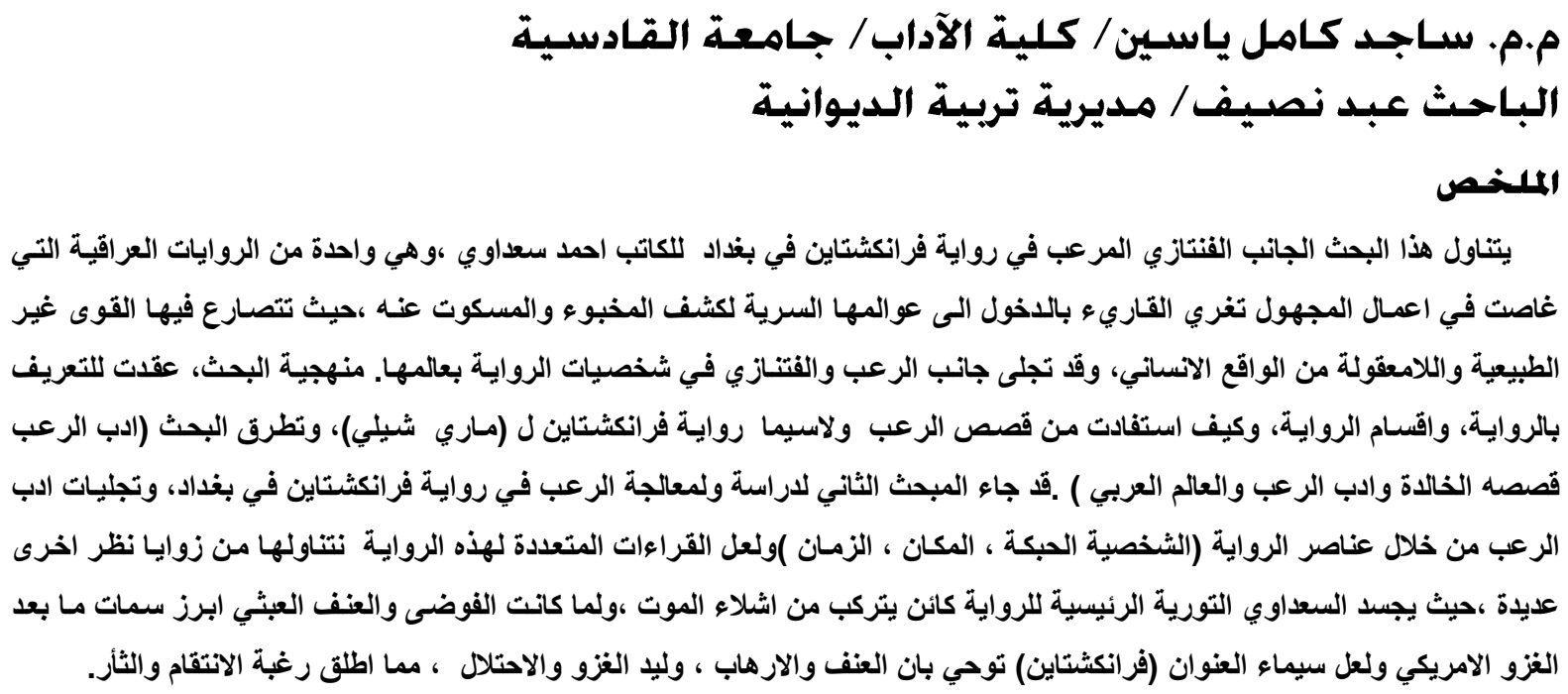

Abstract

Frankenstein's novel in Baghdad has dealt with the reality of living in Iraq with a fantastical instinct, which allows us to reassert its classification within the exotic realism where Ahmad Saadawi created a fantastical and terrifying personality. This fantastical figure emerges amidst the jungle of messy bodies every day by the simplest and most blatant means of the human body. The terrible fantasy event, the beautiful, funny and bloody vision of the Fantasia, is emerging again, in an atmosphere where the language of blood, muffler , the bombing of public places and the killing of those killed by the murderer kill, so in the darkness or in the broad daylight extends the hand of death to snatch whom want, it has the ability to catch, threats and act in a tense climate of hatred, hatred and mutual economic between the spectra of Iraqi society, many personalities pass in the novel and leaves its effects, its questions of existential and its breath in every corner and the place went through, presented in the novel substantially as the equivalent whole of the people, characters have their obsessions , ambitions, and daily concerns. It is an in-depth psychological study of the characters, and a global panoramic image, attractive, those drawn by Saadawi of his vital and active personalities along the pages of the novel. These figures include broker Faraj , the journalist Mahmoud, Baher Al-Saidi, the porter Hadi, Brigadier Sorour, Nawal, Zeina, Nabeel, Daniel Al-Gahaib, Um Saleem El-Baydah, Abu Anmar The owner of the hotel, Farid Shawaf, the magazine's designer, Hazem Abboud, Abu Selim sitting in his balcony watching the movements of passers-by in the street, and Aziz the Egyptian owner of the cafe, Time is very severe resulting from differing moods after the change that occurred after $9 / \varepsilon / \uparrow \ldots r$ emerged various social problems, and was able forces, currents and social events that were suppressed to breathe, show their values and visions that were naturally rising in different directions due to inconsistencies in one vision, and disagreement on a comprehensive national project, from here we can explain the great repercussions that have had disastrous consequences on the Iraqi individual. The Frankenstein novel in Baghdad attempted to approach the time of death, generosity, and cultural breakdown of the society through a near-reality simulation, employing its initial elements in the formulation of its imaginary discourse. We attempted to pursue the rhythm of time and its role in constructing the characters of the novel with its external dimension, Which controls the architecture of the novel trying to look at the significance of the composition in changing the behavior and values of the characters, and knowledge of the structure of the time, according to the time as well as the function performed by the technical template and its effectiveness .

\section{المقدمة}

$$
\begin{aligned}
& \text { كان اختيارنا لهذه الرو اية مرتبطاً بما حققته من صدى واسع وانتشار أفلح في نقل إيقاع الزمن العراقي } \\
& \text { ليس لدى القارئ العربي فحسب بل امتدت رسالته الى اللغات والثقافات الأخرى ، بعد أن تمكنت من الحصول }
\end{aligned}
$$


على جائزة (البوكر العربيـة) ، حيث فـاز الروائي والثـاعر العراقي أحمد سعداوي بالجـائزة العالميـة للروايـة

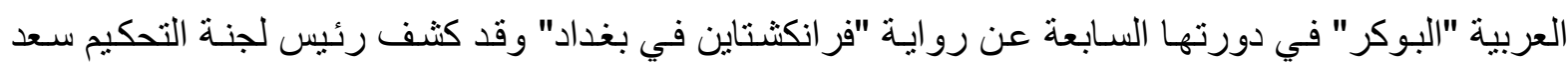

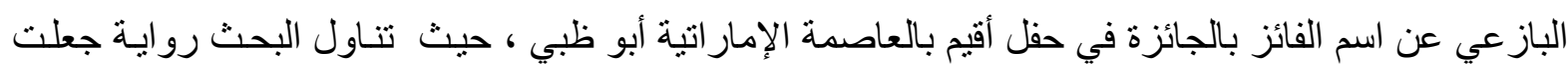

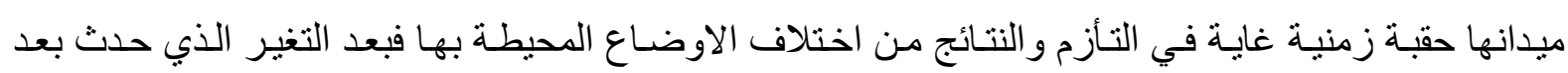

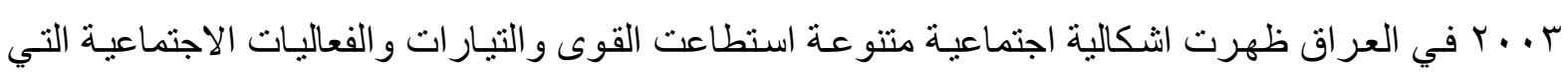
كانت مكبوتة ان تتنفس وان تعرض فيما وراؤ هـا والتي كانت من الطبيعي ان تصب باتبه باتجاهـات متغايرة لعدم الاتفاق على مشروع وطني جامع ، لقد قام البحث على مقدمة وتمهيد ومبحثين وخاتمـة تتضمن ابرز النتائج

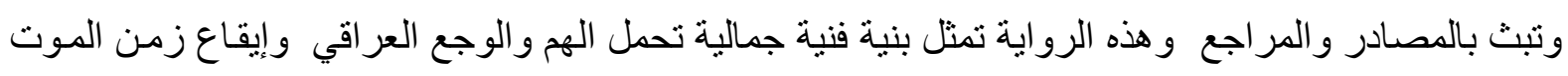
الذي ألقى بظلالـه على حيـاة العر اقيين وهـ يتحركون ويعيشـون ضــن تجاذباتهـا، ومـن المعلوم أن للرؤيـة الفتنازية في الرواية أهمية كبيرة في صياغة خطابها وفي دلالة محمولها الثقافي ، وتعد عملية تقليب الزمن من زواياه المختلفة ذات أهمية كبرى فهي تقرأ العمل من زاويته التقافية ومـا يمكن أن يمد بـه مجتمعهه من رسيائل

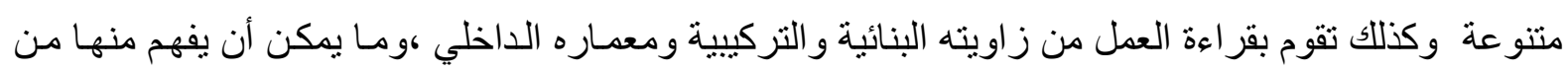
دلالة مختلفة ستكون حتماً قر اعة ابداعية متعلقة بما يمكن ان يستتنجه قارئ و احد وبذا فهي تتيح المجال مفتوحاً لقر اعات أخرى متعددة .

\section{نظرة في عالم الرواية}

للرو اية اهية كبيرة في نقل هموم الناس بصيغة ادبية ،او يقوم الكاتب من خلالها بعرض روايات تتخطى الجوانب الحقيقية الى جوانب خيالية ،فهذه الرواية كانت انموذجا لهاجس ير افق اغلب افر اد المجتمع العر اقي في لهي

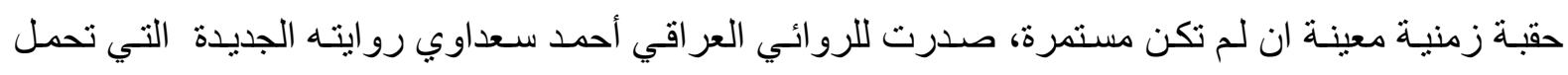

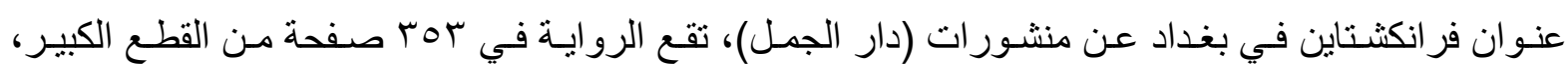

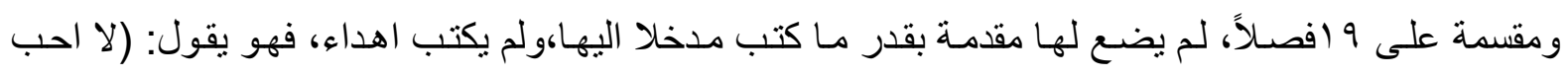
وضع مقدمات للروايات بقلم كاتب غير مؤلف الرواية. هناك مدخل في الرواية و 19 فصـلاً، ولكن المدخل هو

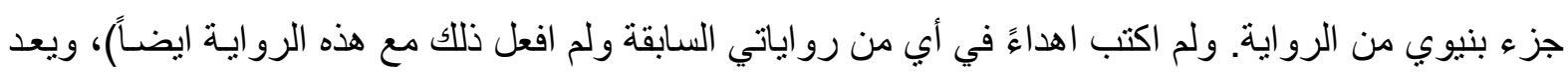

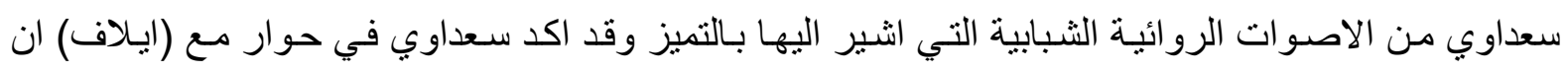
الرواية استفادت من قصص الرعب كأدب شعبي معروف عالمياً مثل روايـة (فر انكثتناين) للكاتبـة البريطانية

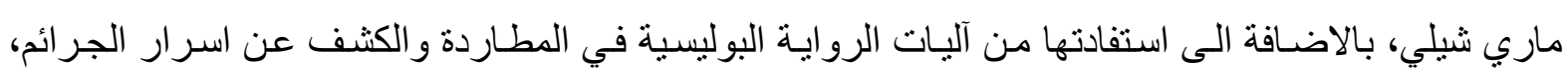
و البلاكك كوميدي وتوظف كل ذلك ضمن إطار استعاري متر ابط يحيل الى قضـايا متعددة في الواقع العر اقي

اليوم.

- حدثني عن فر انكشتاين الخاص بك، واي اوجه تشابه واختلاف بينه وبين فر انكثتاين ماري شيلي؟

مجرد أن تتحدث عن جمع بقايا جثث لخياطة كائن جديد ينهض حياً، فان الذهن يذهب مباثـرة الى قصـة فر انكثتاين، هذه هي الصلة الوحيدة او فلنقل الاستعارة ولكنها تدخل داخل القصـة العر اقيـة، في سياق مختلف 
تماماً. لقد قر أنـا وتابعنـا و عايشنا مستوى غر ائبي في الاحداث العر اقيـة خلال السنوات الماضية بصعب على

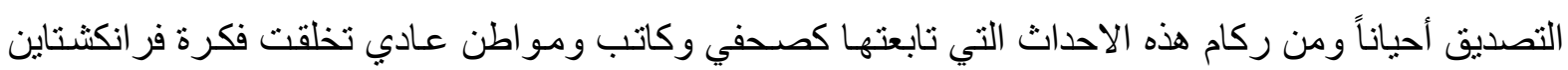

البغدادي(')

اهتّم الروائيون لاسيما في الآونـة الأخيرة بالقيمـة الفنيـة للشـكل الروائي، ممـا أدى إلى ظهور أنشكال

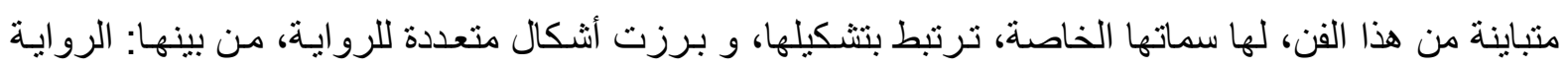

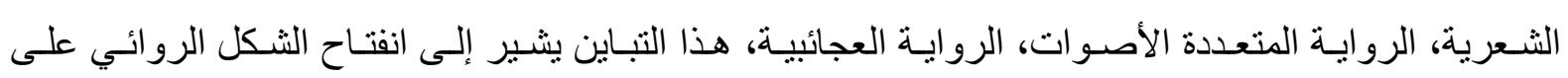

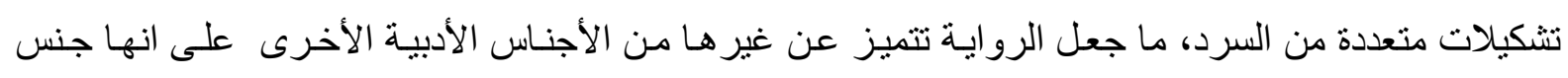
ادبي لم يكتمل لحد الان.

ولعلّ نركيزنا في هذا البحث على أحد الأشكال الروائية، ألاو هو الروايـة في ادب الرعب، سيفتح

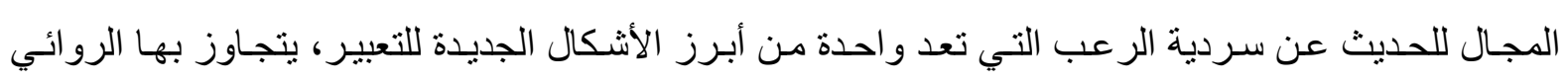
الإطار التقليدي للحبكة السردية وانطلاقا من ذلك ينشأ مظهر من مظاهر التغيير في الثكل الروائي، و وإن كانت

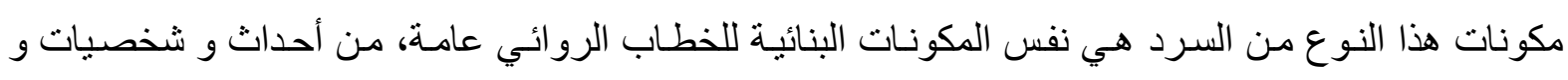

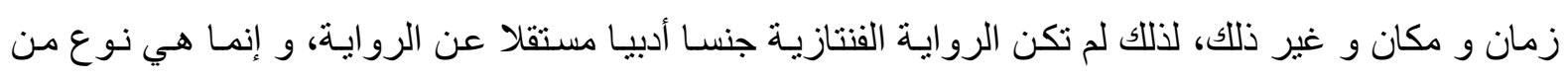
أنواع الرواية الحديثة، إلا أن ادب الرعب يتضمّن اختلافاو شكلا جديدا من السرد، و يشكل حضور ا قويـا في

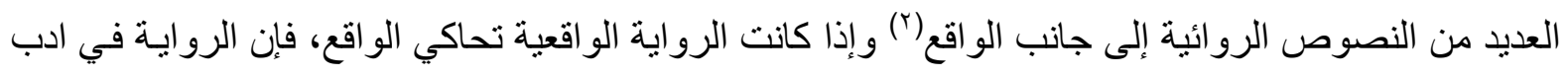
الرعب تتجـاوز هذا الو اقع إلى اللاو اقع واللامنطق، من خـلال خاصيتي التعجيب و التغريب، و قد تباينت وجهات النّظر في النّقد العربي حول وضعية الفنتازية من حيث ضبط المفهوم الخاص بهـتعد روايـة فر انكثتاين

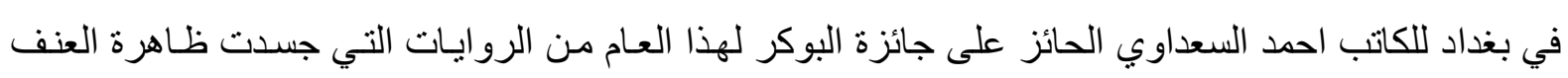
الدموي في ابرز اشكاله فالكاتب يبدأ الفصل الاول من روايته بحدوث انفجار قائلاً: (( حدث الانفجار بعد دقيقيتن من مغادرة باص الكيا الذي ركبت فيه ام دنيال )) يقوم السعداوي في روايته تشريحا اجتماعيا ونفسيا لدلالات العنف الدموي مـن خـلال عدة ابطـال تختلف ردود افعـالهم على واقع الدمار يتشـكل بطل الروايـة المجهول الاسـم والهويـة الملقب بالثسـة (فر انكثـناين) و ( المجرم ) ( اكس) و هي شخصية فنتازيـة تشبـاه شخصية( فر انكثتاين) مـاري شيلي تتجسد باشكال رعب تتكون من اللامعقول وهي بقايـا اعضـاء بشرية قام

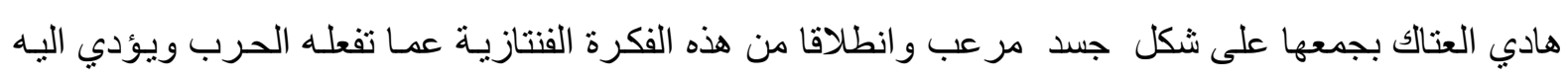
العنف ينسـج النص احداثـه و افكاره يشـق السـعداوي مسـار حيـاة بطلـه المتخيل الثسمة وبطلـه الـو اقعي هـادي

العتاك(r) (

\section{المبحث الأول- مرجعية أدب الرعب المباك}

أدب الرعب (Harror Fiction ) قصصه اساطيره الخالدة

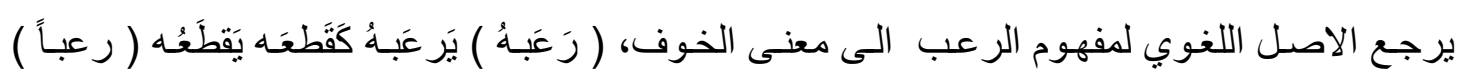

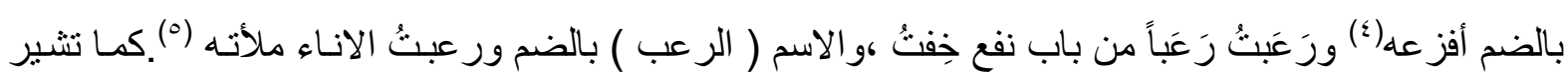


اغلب المقاربات الاصطلاحية الى انها حالة استيلاء الخوف على القلب حيث يسلب الامن بالكلية أو حالة من الحالات النفسية التي توجد داخل الانسان فقد يشعر الانسان بالر عب من حالات عدة منل الظلام و الوحدة ،والذي قد يترك حالات سلبية مثل الهلوسة والحالات النفسية والتفكير السلبي قال تعالى(سنلقي في قلوب الذين كفروا

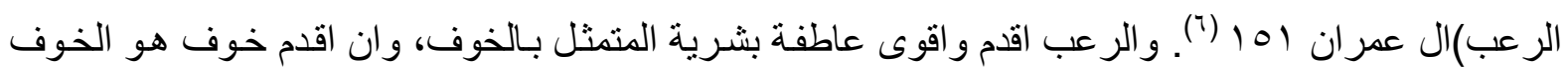
من المجهول وهو ما ذهب اليه الكاتب الامريكي (هوارد فيلبس لافكرا فت) الذي اشتهر بكتابه قصص الرعب

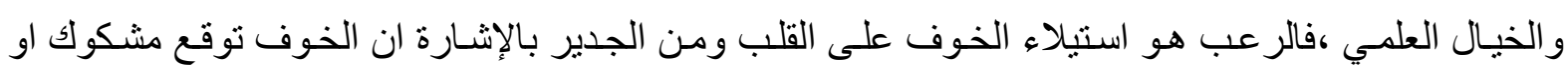
مضنون و هو يقابل الامن والرهب استمرار ذلك الخوف والفزع هو حصوله مفاجأة بحيث يوجب الاضطر اب

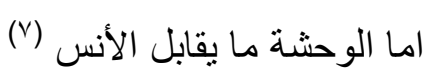

لا احد يعرف تحديدا متى بدأ هذا النوع من الادب ولكن اغلب الباحثين يعتقدون انه قد بدأ منذ زمن

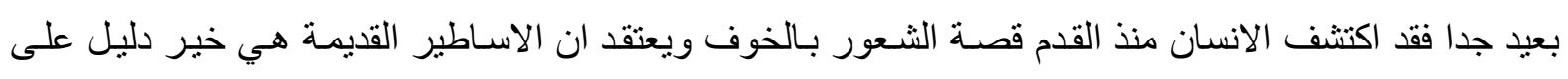
ذلك فقد كانت تحوي على كم لا بأس به من القصص التي تهدف الى اثـارة هذه المتعـة لدى المستمع او القارى

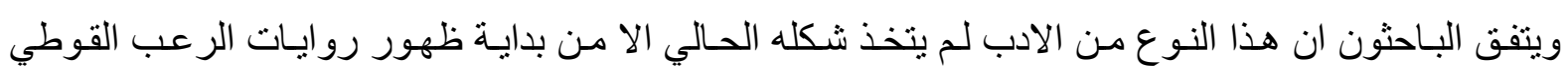
الثهيرة التي تحكي قصص في اجواء مرعبة قديمة حوت ـ عملاق ـ البرق واضو اء الثموع(^) ـ حيث لم ينل فئل ادب الرعب انتشار اوشهرة واسعة الا بظهور مـا يعرف بـ الروايـة القوطية وهو جنس ادبي يرجع الباحثون

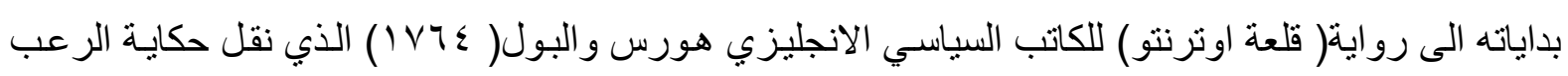

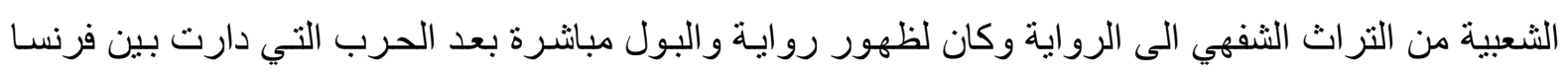
وبريطانيا وحصدت اكثر من مائة الف قتيل حملها ابعادا سوداوية ورموزا اقل ما يقال فيها انها مزيج من القلق

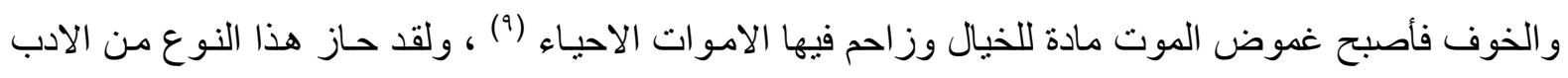
شعبية واسعة جدا في نهاية القرن الثامن عشر وبداية القرن التاسع عشر على يد كل من ( آن راد كليف ) التي كتبت قصـة (Mysteries of dolpho) وهورس وبليس صساحبة روايـة (Horace walpoes) وكان لرواية

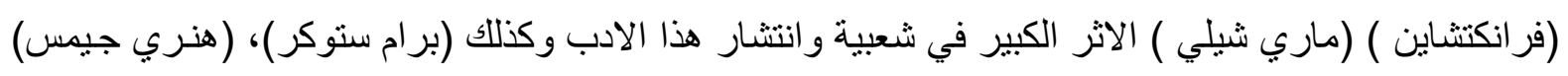

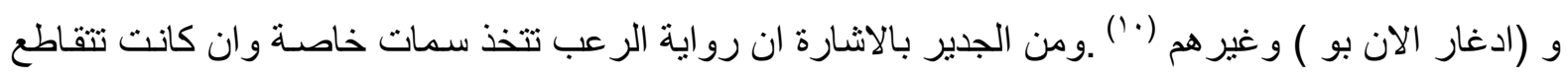
مـع الروايـة البوليسية في اللغز ومنهـا الرعب النفسي والجسـي واللغز والاشـباح و البيوت القوطية الظـلام

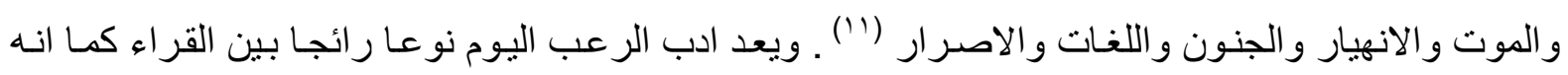

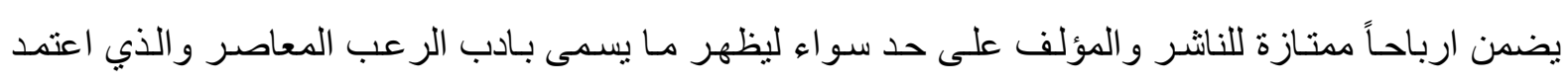
بصورة كبيرة على على العنف الدموي مما اخر هذا النوع كثير بـادب الرعب وجعل بعض الدارسين و النقاد ينظر اليه نوع من أدب الدرجة الثانية ولكن هذا لم يمنع عن ظهور نجوم اعادوا لهذا الادب هيبته امثال كاتب

الر عب ستيفن كينج وكلايف باركر (r') .

أدب الرعب والعالم العربي 
أمّا في الأدب العربي، فنجد أولى بدايات السّرد الفتنازي و العجائبي تتجلى في القصة القر آنية، كنوم فتيـة

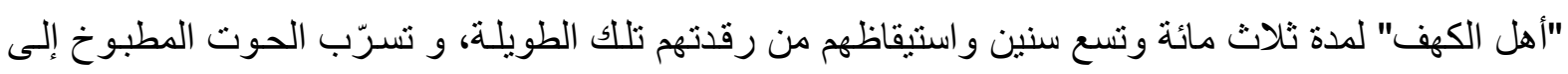

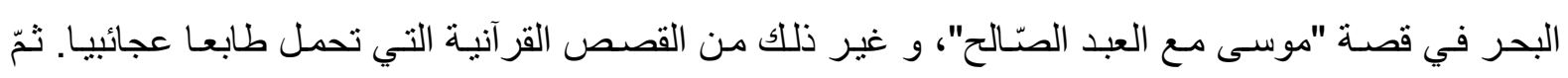
قصص ألف ليلة و ليلة و ما تحمله من حكايات عجيبة خارقة للنظام البشري، و كليلة و دمنة و السير الثـعبية، كسيرة فارس اليمن سيف بن ذي يزن، و سيرة الزير سالم و عنترة بن شداد، و غير ذلك. ومع ظهور الروايـة العربيـة الجديدة، حاولت هذه الأخيرة التّجريب لكسر النّّط السّردي و تأصبل الرواية العربية و ربطها بـالتراث العربي القديم، قصد ارتياد آفاق العالمية عن طريت تمويـه الواقع و السّمو بالخيال. و لعل العوامل السياسية و الواقع التاريخي اسهمت في ظهور ادب الرعب و وإثرائها، فحاولت التعبير

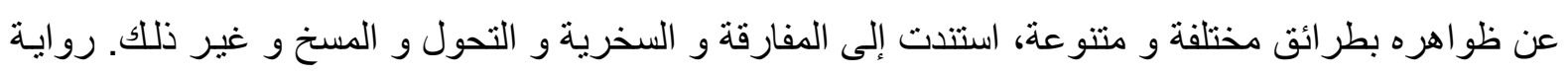

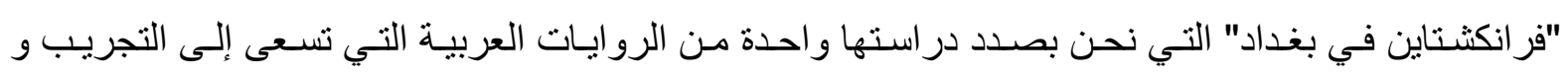
التحديث من أجل تأصيل الروايـة العجائيية ويحفل التراث العربي بالحكايات المثيرة عن عالم السحر والجـان و الاسـاطير وقصـص مـا وراء الطبيعـة سـواء في الحكايسات الثـعبية الموروثنة او في كتـاب الف ليلـة وليلـة

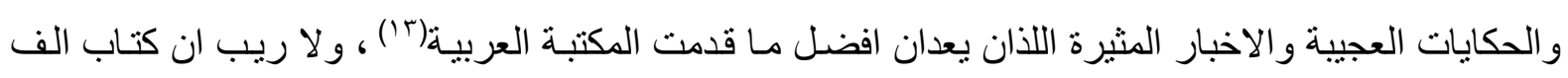
ليلة وليلة يعد من اشهر الكتب ذات الطابع الثعبي والبنية التعجيبة حيث يقوم على وصف عو الم فوق الطبيعة داخل عالم طبيعي مألوف وشخوص كثيرة يتخذون هيئات كثيرة أي يطالهم الامتسـاخ والتحول ممـا يدعي الى لى

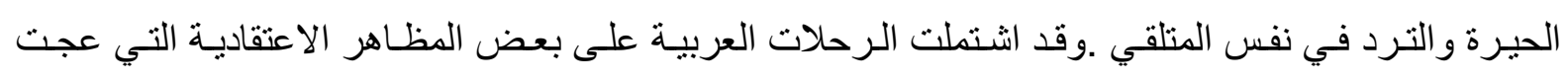
بالمظاهر السحرية ومشاهد الرعب و الغريب المنتشرة في الهند خاصة و التي تفنن الرحالة في رسم شخصياتها وممارستهم الثـائعة ومن هذه الرحلات رحلة ابن بطوطة اذ يقول فيها (( رحلنـا من مدينـة كاليور الى مدينـة

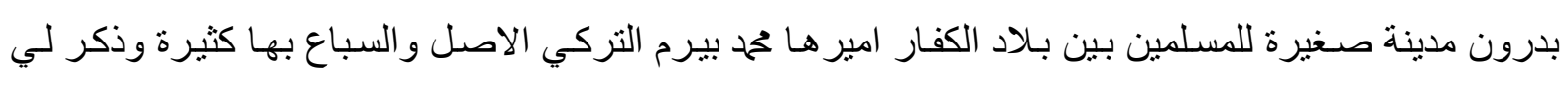

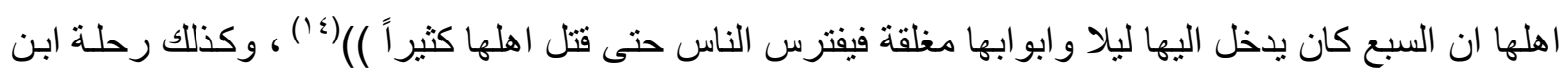
فضلان التي تحكي حكاية رجل عظيم الخلقة الذي اخبره به ملك الصقالبة فكان من حديث الملك ان النهر اخرج اليهم في الزمن الماضي رجلا على غير هيئة البشر اذا نظر اليه الصبي مـات واذا نظرت اليهـ المرأة الحامل

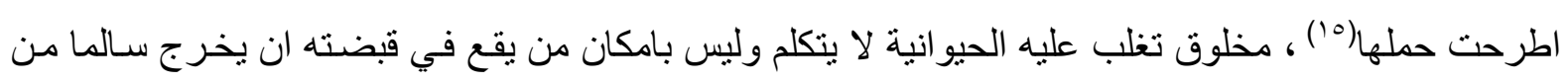
بين يديه

ويروى عن كتب الرحلات عن الممسوخات وهي كائنات ناتجة من تركيب اكثر من جنس او تكون

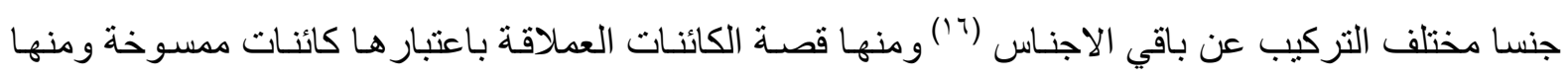
قصة العملاق الذي تحدث عنه ابن فضلان في رسـالته أبي حامد الغرنـاطي الذي تحدث عنه في تحفة الالباب (V') ، وكذلك الجن وهي كائنات عجيبة وغريبـة حملت اوصسافها كتب العجائب و الغر ائب في كتب الرحلات القديمة لان اصحابها ارتادوا الاصقاع البعيدة مرتع كل غريب و عجيب (^’) لكن على الرغم من ذلك فان و لادة ادب الرعب في الوطن العربي متأخرة ويرجع تاخر ادب الرعب الى استحواذ الروايات الاجتماعيـة والبوليسية 
خلال فترة كبيرة من القرن العشرين لكن في تسعينات القرن الماضي قدم الكاتب المصري احمد خاللد ( سلسلة ما وراء الطبيعة ) كأول عمل ادبي للرعب في الوطن العربي وشـهدت مصر في السنوات الاخيرة اقبالا من

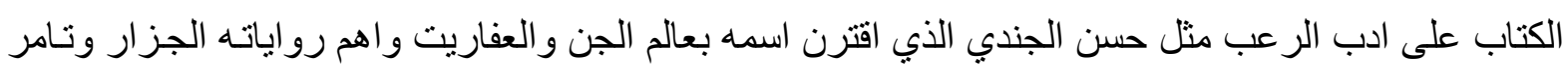

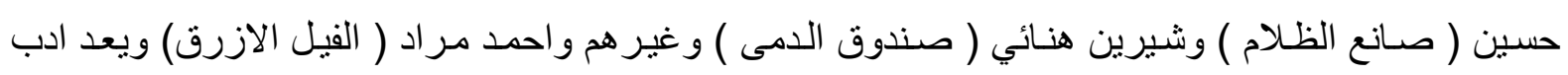

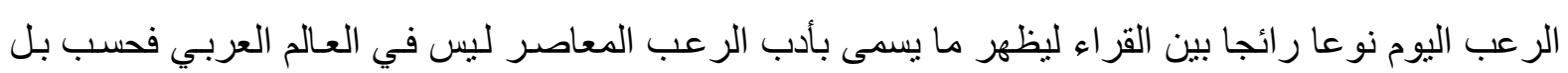
العالم كله (19)

\section{المبحـث الثاني- الجسانب الفنتازي في رواية فرانكشتاين في بغداد} لمحة عن الرعب في رواية فرانكثتاين في بغداد

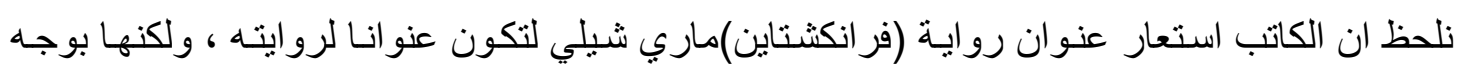

اخر على الرغم من تثـابه العملين من ناحيبة الغر ائبية والعجائبيـة ليكون هذا تـاتثرا و واضحا من خـلال احداث

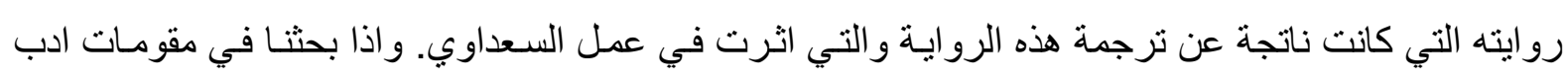
الرعب الذي يتميز بالانزيـاح والخروج عن المـألوف وحالة استيلاء الخوف على القلب من المجهول والذي يتجاوز الو اقع الى المتخيل ليكتب نصا مترددا بين عوالم الحقيقة ،علمنا ان تودوروف اعتبر ادب الرعب وسطا

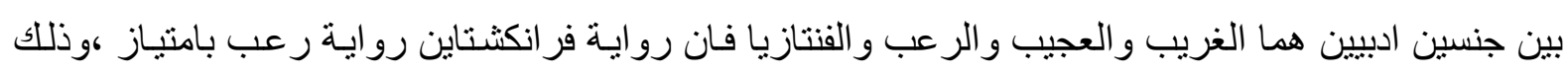
لان الخوف و الفتتازيا سمة بارزة فيها تشكيلا ودلالة ووظيفة بطل الرواية هو مو اطن عراقي اسمة هادي العتالك يسكن حي البتاوين وسط بغداد بـائع الاجهزة العتيقة والمستهلكة والمستعملة مواطن يعيش وسط التر اكمـات

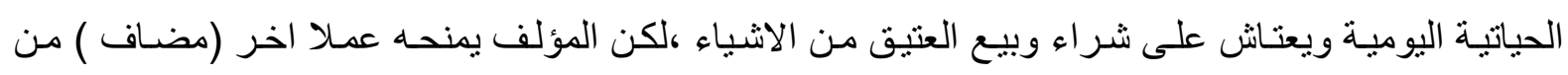
الو اقع الذي يعيش وسط تداعياته حيث اعمال العنف الاجتماعي ويحدد لهذه الاعمـال زمنـا واضحا وخـلال شتناء

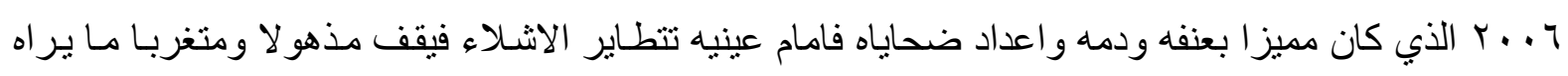

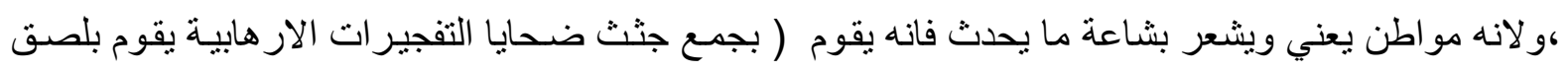
هذه الاجز اء لتنتج لنا كائنا بشريا غريبا سر عان ما ينهض ليقوم بعملية ثنأر وانتقام و اسعة من المجرمين الذين

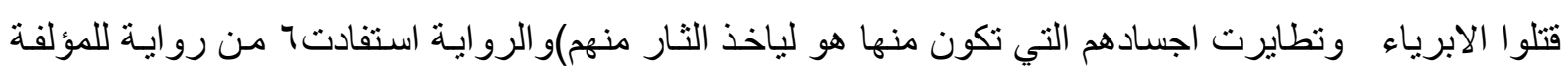

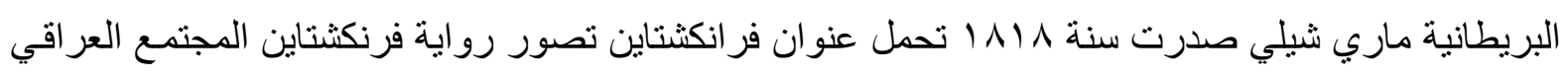

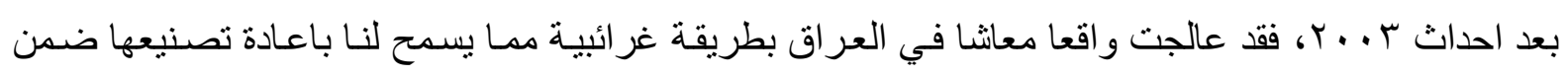

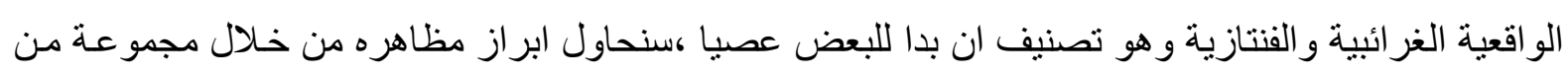

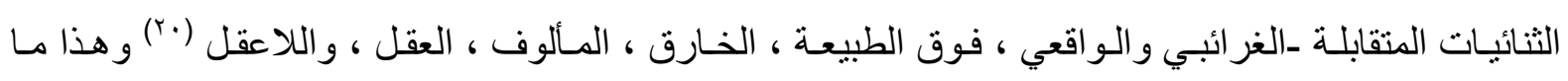
يتجلى من خلال عناصر الرواية التي سيتم تناولها في هذا البحث .

الشخصية

يقترن الخطاب الرو ائي الحديث بالثخصية باعتبار ها عنصر ا مهما ومركز ا سـاندا تدور بقيـة العناصر في فلكها، فلا قيمة لبقية العناصر الا بتفاعل الشخصية معها فالثخصية من دور ها تكون على نوعين الثخصية الرئيسية وهي الثخصية التي تدور كثخصية اولى حولها احداث الرواية وهي معقدة بسبب مـا يربط منها من 
احداث ومـا يدار من تصـرفات ،و الثخصية الثانويـة التي لا يتركز دور هـا في الروايـة ولكن حضور هم للدعم

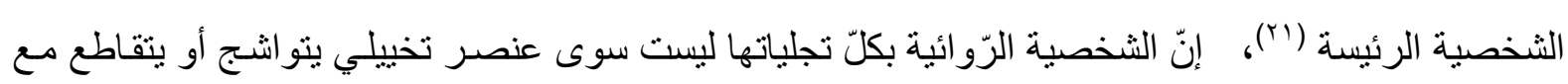

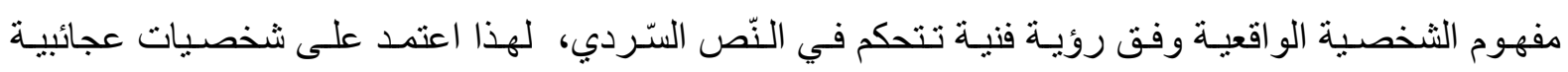

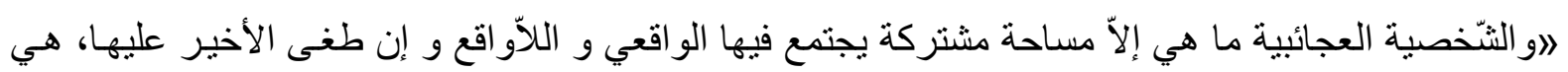
تقنية فنية استخدمنها العجائبية الحديثة لتعبّر عن أزمة الإنسان المعاصر ، لذلك جاء البناء الفني لهذه الثخصية

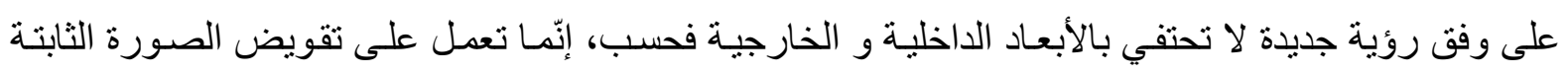

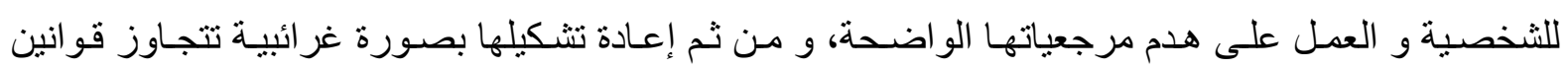
الو اقع.

وقد عبرت رواية فرنكثتاين في بغداد عن و اقعها الفتنازي المرعب تعبير ا بليغا ولقد اثرت الدلالة

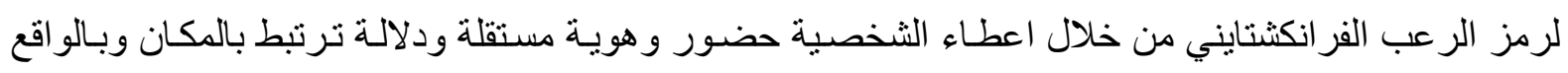
السياسي الاجتماعي(rr) نسج احمد سعداوي شخصية فنتازية مر عبة بجعل بطلاها الاساسي شخصية غير مألوفة من السرد العربي فهي شخصية مكونة بطريقة غر ائبية فنتازية من اشلاء ضحايا التفجيزات التي خاضهها هـادي العتاك ،مكون من جزازات بشرية تعود لمكونات و اعر اق وقبائل واجناس منباينة حيث تم وضـع هذه الجثنة بطريقة مر عبة صيرت صناع الجثة(rr) ((هذا العمل البشع الغريب الذي قام به لوحده دون مساعدة من احد و لا يبدو مبررا ومفهومـا)(ع (ب) حيث اختار الصانع اسم الثسمة ويمثل الثخصية الفنتازية الرئيسة والغامضة والمجهولة و المخيفة لانها لم تكن جثة دئة فعلا فاطلق عليها ( الثسمة ) هذه المفردة التي توضـح الذي لا اسم لـه ((فهو بسمي الكائن الذي صنعه بيديه باسم الثسمة لانه ليس جثة فعلا الجثة تشير الى كائن او شخص محدد وهذا مـا لا ينطبق على الثسمة )( ) (ro) .

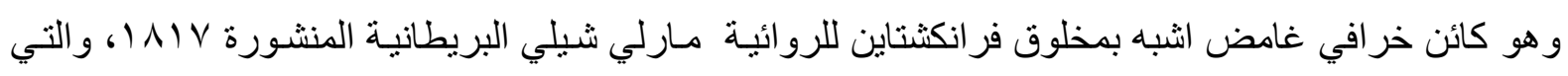
بطلها فكتور فر انكثتاين المتخصص بالعلوم الطبيعة والذي يرغب في بث الحياة في احد مخلوقاته غير الحية

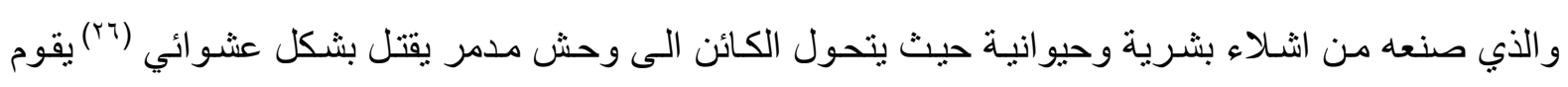
(هادي العتاك) بطريقة مشابهة في رواية فر انكثتاين في بغداد، بجمع اشـلاء ضحايا التفجير ات وسط هذا الدم البريء المهدور وسط غابة العبث من الجثث المتساقطة كل يوم بشتى الوسـائل (( تفخيخ الجسد الادمي ، تلغيم

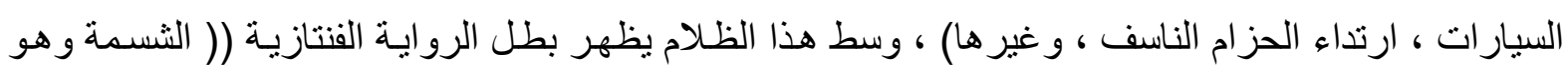

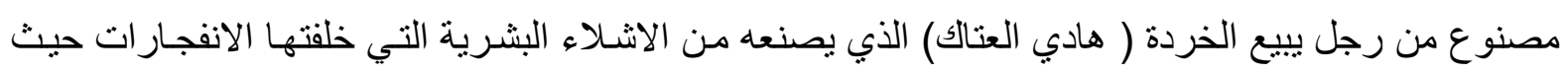

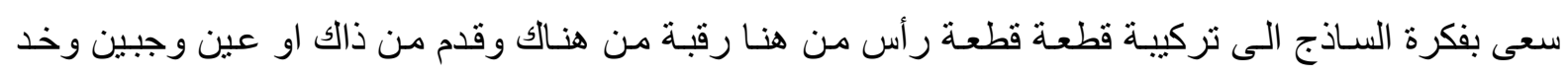

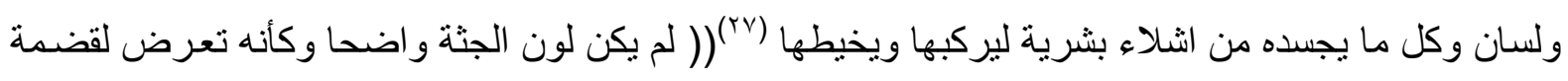

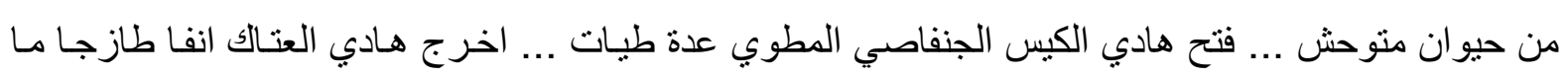

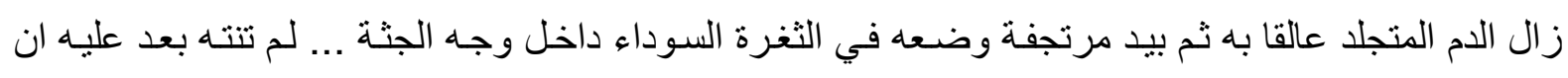
يخيط الانف حتى يثبت في مكانه ولا يقع)) (^^) ، حيث يقوم هـادي العتاك بجمـع الارجل و الايـادي المتناثرة 
جراء العمليات الارهابية ،فينطلق وحش بغداد المخلوق من اعضاء الابرياء واجسادهم ،ذلك الوحش الذي خلق

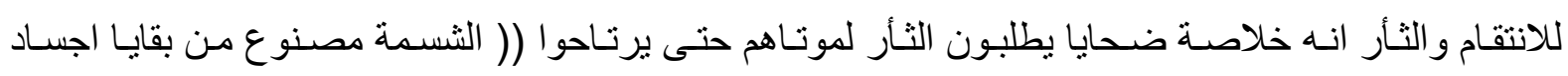

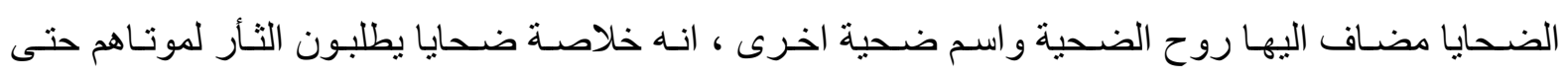

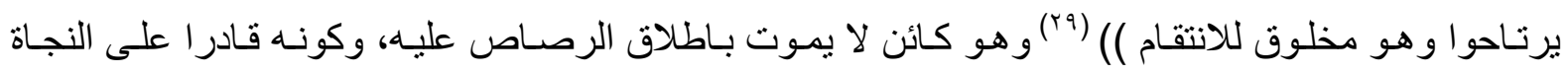
وتبديل ما فقده من جسده من قطع غيار من جثت اخرى تسقط يأخذها ليثأر لها ((هناك اخباريـات عن مجرمين يتم اطلاق النيران عليهم ولكنه لا يموتون ... يخترق الرصاص رأس المجرم او جسده ولكنه يستمر في السير

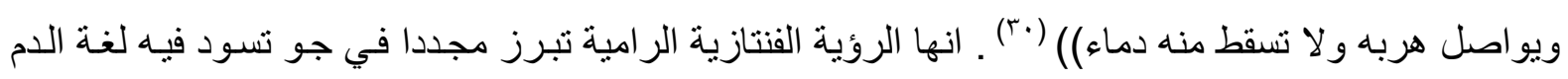
و القتل من يهوى القاتل قتلك هكذا في الظلام وفي وضع النهار تمتد يد الموت لتخطف من تشـاء ('آ). ((تحدّث

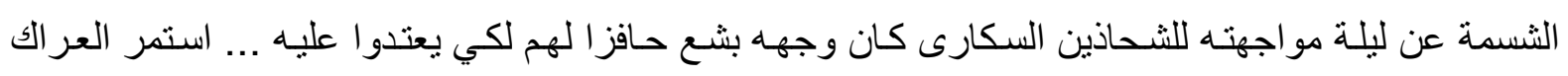

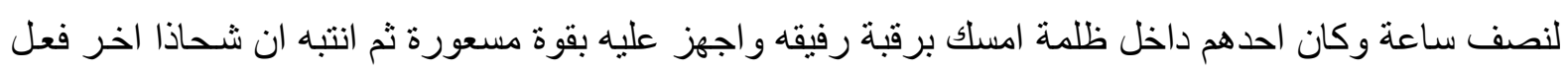

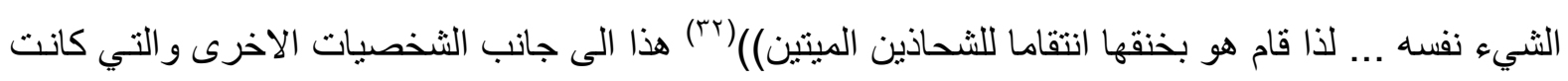
مؤازرة ومنحازه لوحش بغداد و افعاله كانو ا من شذاذ الافاق، الذين يرون فيه عملا مقبو لا من خـلال الانتقام من المجرمين حيث يظهر الجانب الخيالي الفنتازي تستعين دائرة المتابعة و التعقيب باثخاص من فل فلكيَن و المنجمين

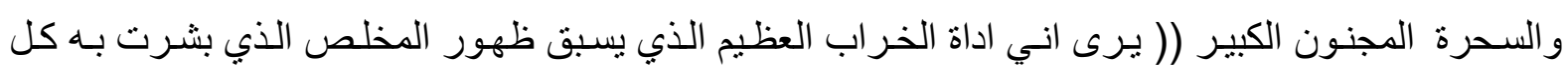

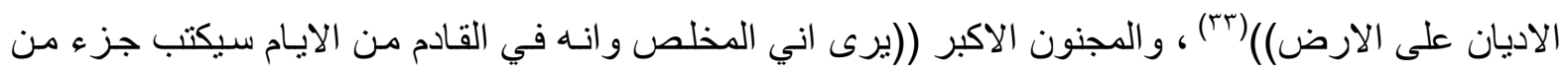
صفاتي الخالدة))(؟)، والسفسطائي ((انه بارع في تبرير الافكار الجيدة والترويج لها وتلميعها وجعلها اكثر قوة ولضاعة وبـارع في عمل ذلك مـع الافكار السيئة))(ro) ـو السـاحر: هو رجل عجوز ((هو رجل عجوز كان الساحر يسكن في شقة في حي ابو نؤاس انه يقول انه كان من ضمن سحرة الخاصـة برئيس النظـام السـابق وانـه

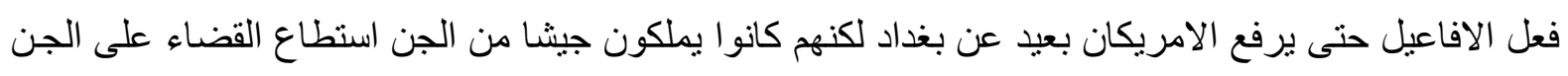

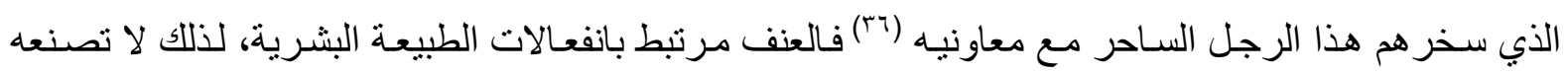

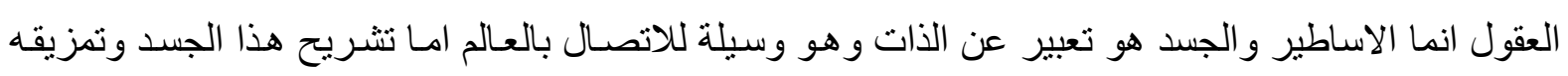
وتحويله الى مستخ فهو تثريح سياسي (التمزف السياسي) الذي شـهده الواقع العر اقي بعد الاحتلال الامريكي للعر اق يقول فوكو: (ان اهم الوسائط التي تم استخدامها لتحرير سلطة مغلقة هو الجسد و عليه امتلاك اثـلاء اجساد الاخرين هو تشكيل كيان سياسي ممزق لان الجسد وسيلة لاستنطاق السلطة)

الحبكة

الحبكة هي بنية او النظام الذي يجعل من الرواية بناء متكامل، بمعنى انها سباق على درجة من القوى

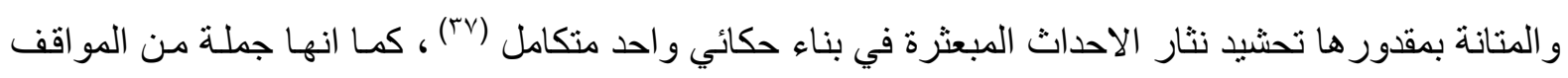

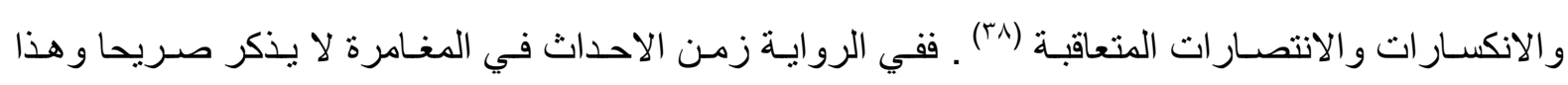

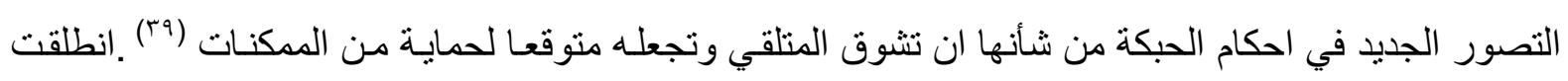
الرواية الانجليزية للروائية مـاري شيلي من حكاية ( فيكتور فر انكثتاين ) الذي تمكن من اختر اع كائن جديد عملاق انتفض يروم الانتقام من الطغاة و التخلص من زعمـاء العشر ،ياخذ سعداوي هذه الحبكة و أصل الفكرة 
لينزلها من جديد في فضائه البغدادي سنة ه . . ب اثر الغزو الامريكي للعراق ،فانطلق من واقع فعلي ووقائع

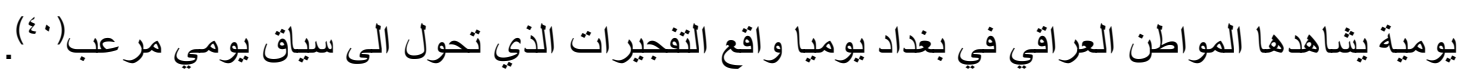
(حدث الانفجار بعد دقيقتين من مغادرة باص الكيا ... وشاهدو ا من خلف الزحام وبعيون فزعة كثافة

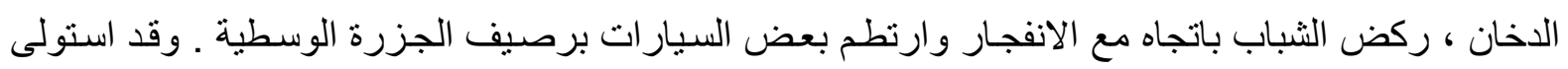

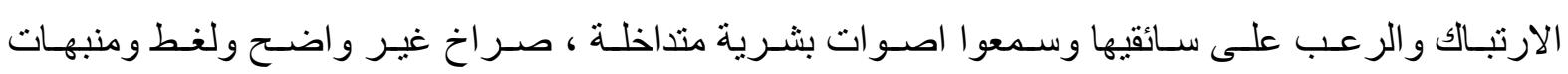
سيار ات...)( (أ) وممـا يكسب الروايـة جاذبيـة انها تعتمد على تقديم حبكة وحدث ينتميـان الى مـا يسمى بفن الغزوتسك (Grotesque) الفن الذي يميل الى خلق شخصيات غريبة وخيالية واحيانا مخيفة كما هو الحال في فيلم ( مصاصوا الدماء ) (افاتار) ، اذا بدأ المتلقي يميل الى الروايات التي تلتقط مواقف غزوتسكية تثير الرعب و الهلع ((فهذه الاشباح التي كانت تحوم فوق الجسر هي اشباح راقدة من جسد الانسـان تتام وتسببت في جسده

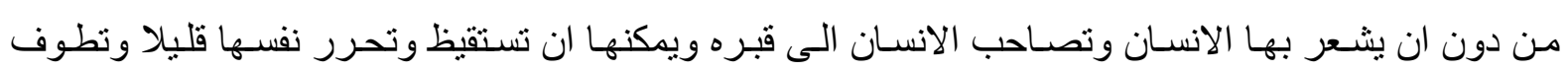

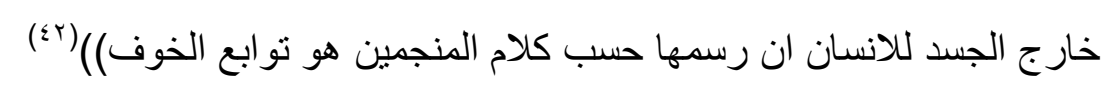

فالرواية تنطوي على اكثر من مستوى ،فهناك جانب المستوى الغرائبي الفتتازي المهيمن و الذي تحتل

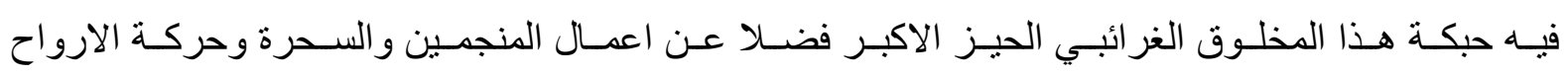
الهائمة.)(هناك شخص واحد يقف ور اء هذه الجر ائم كلها... جاءه كبير المنجمين بخبر سعيد لقد توصل الى اسم هذا المجرم ، سخر الجان والتوابع واستثمر الاسرار البابلية في التنجيم و علوم الصـابئة المندائيين...انـه الذي لا لاهيل

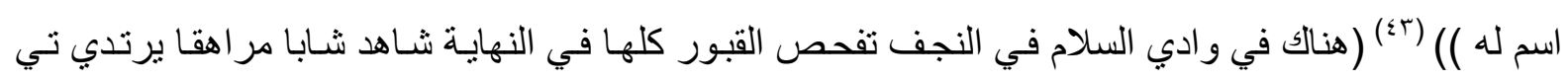
شيرت احمر .... (1) لماذا انت هنا ... عليك ان تبقى بجوار جثنك

ـلقد اختفت ـ كيف اختقت ؟ لابد ان نجد جثتك او أي جثة اخرى )) (؟؛). و هناك جانب من المستوى الو اقعي اليومي وهو ما يكثف عن شرائح عر اقية تعيش في رقعة اجتماعية صغيرة من البتاوين لكن هذا المستوى قد تعرض الى

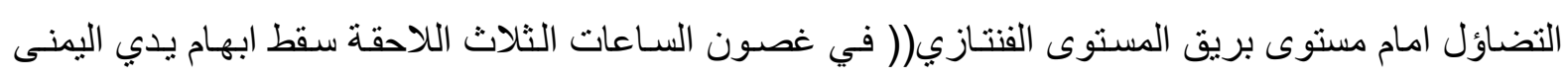
وثلاثة اصابع من بدي اليسرى ذاب انفي وتكونت ثغر ات كبيرة جسدي بسبب ذبول اللحم فيها )) (0؛ . الفضاء الفنتازي و تحولاته: إنّ مفهوم الفضـاء يتّسـع ليشـمل الزمـان و المكان، و وجهة النظر، فالفضـاء هو الحيّز الزّمكاني الذي

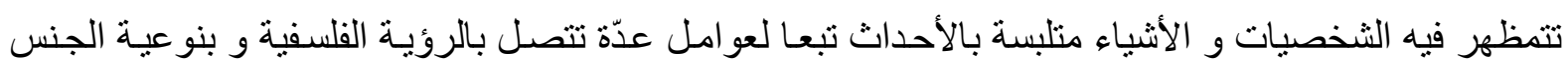
الأدبي و بحساسية الكاتبه. 
يلعب المكان دورا مهم في التركيب البنائي للرواية، حيث يعد من العناصر المهمـة تعبيريـا في أبي عمل

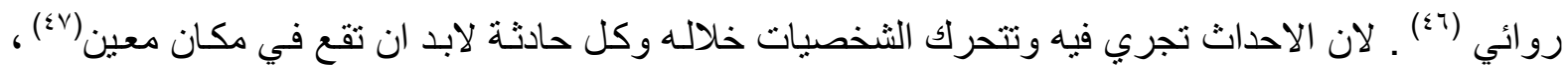

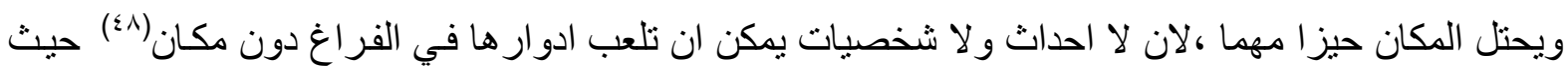
لم تكن الانواع القصصية السابقة للرواية تستمد كلامها من حدود في المكان مضبوطة ومن هنـا جاءت الروايـة

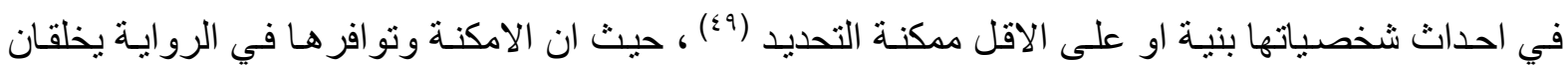
فضاء شبيهاء بالفضاء الو اقعي فكان بلز الك بصف شوار ع حقيقية تجعل القارىء يقوم بعملية قياس منطقي (·) ، وفي رواية فر انكثتاين في بغداد لاحمد السعداوي نجد ان البعد المكاني الذي حفلت به الرواية قد تميز بالمشـاهد الفتنازيـة و الاثارة و عناصر التشويق التي منحت من تقنيات الفن السينمائي الكثير ، اللقطة البـاهرة و الصدمة المحفزة للافكـار بالصيخة المرسومة للشخصيات جميعـا وهم يتحركون ويتحرقون الى كثف مصبير الاخر المنزوي و المبتعد و التابع في امكنة الخطر ودائرة الثبهات و الاجر ام مثل سكن كتائب السحرة والجن في مبنى قديم في منطقة الدورة و هذا ما نلاحظه في بيت العتاك الذي تم صنع المخلوق ( الثنسمة ) فيه (( دخل الى بيته وبيته هذا وصف مبالغ فيه ... انه ليس بيتا على وجـه الدقة فأغلب مـا فيه مهدم وليس هنـاك سوى غرفة في العمق ذات السقق متصدع ... كانت الغيوم قد انقتعت تمامـا لان تيار ات هواء عالية بدات تهب على شكل

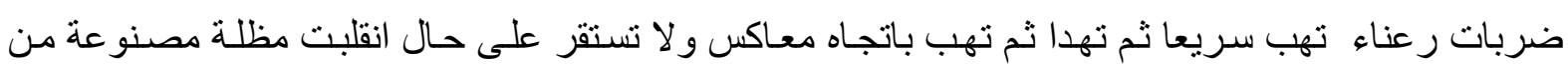
حديد والقماش))(1) . ((احيا الظلام وموجودات غرفته المبعثرة الضاجة بالجرذان .......وسمع حركة ما تصدر

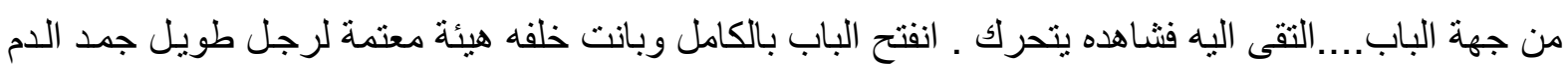
في عروقه وهو يرى هذه العيئة... نزل الثبح على السلم وشـاهد القط نـابو في سـاحة البيت الداخلية.....كان

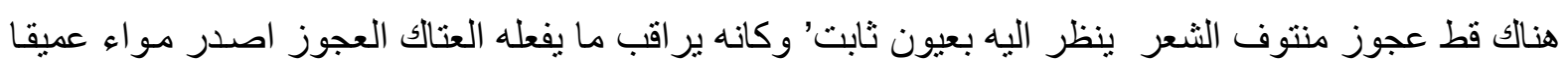

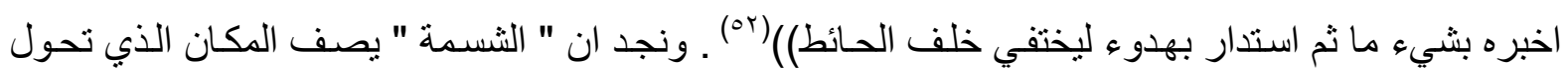
اليه و هو ذات مدلول يبعت على الريبـة والثك والخوف (( اسكن الان في عمارة غير مكتملة البناء ... و هو مكان تحول ساحة معركة ... و لانها سـاحة حرب فعلية فهي خالية من السكان و لانها خالية من السكان فهي المكان المناسب لي(م) (ضرب الضوء الاصفر للفانوس على وجه الرجل الغريب فبانت ملامحه بوضوح وجها مزر بقطب خياطه وانف كبير وفم مشقوق مثنل جر ح)( (ع) . حيث نجد ان هذه المنطقة قد عاشت صـراع مذهبي وطائفي صـر اعا دمويـا ،ممـا جعل من بيوتها المهجورة مرتعـا للفئات الضـالة والمتحاربـة وكان الناس الابرياء وقودها خطف ، وقتل وتفجير حيث نجد في هذا الحيز المكاني الذي يتقاسمه زمن الحرب الاهلية تفاعل البعد الفتتازي وخياله ليدير هذه التجربة المريرة ((في اليوم التالي بعد ان فطرت و غسلت مو اعينها ومـا جاهـا الهدير المز عج الطائرات الاباتشـي الامريكية وهي تمـر بصـب فوق الزقاق..... ربمـا هو اقوى انفجار في

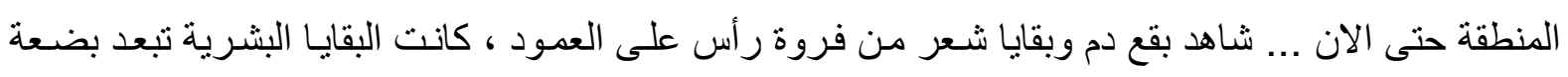
اشبار عن انفه وشاربه الابيض فداهمه شيء من الخوف ـ كان الانفجار فظيعا لقد خـارج هـادي راكضـا ارتطم

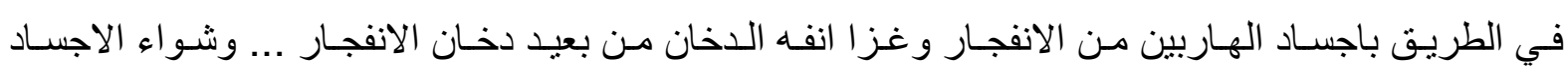


........ الههم انتبهوا في اللحظة التي غدا فيها كتلة من اللهب والدخان تاكل السيارات...مع تناثر الزجاج وتخسف الابو اب وتصدع جدران البيوت القديمة) (00) ـ انها الرواية الفتنازية الدامية تبرز مجددا في جو تسوده لغـة الدم و الكاتم و التفجير ات و الاماكن العامة وقتل من يهوى القاتل قتله .

يعتبر الزمان عنصر ا بنائيا مهم في جميع فنون القصص ،اذ يعد محور الرواية و عمودها الفقري الذي

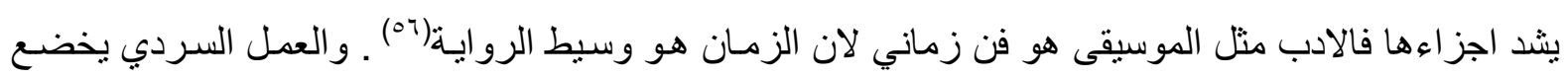

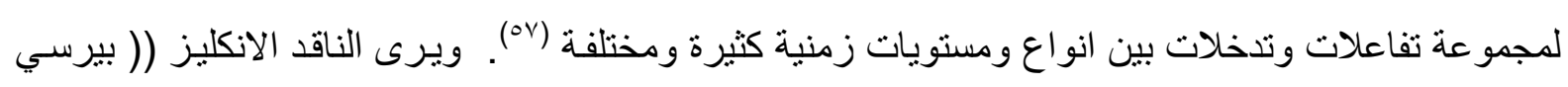
لوبوك )) انه ليس ثمة اكثر صعوبة في تأمينه داخل الرواية من الزمن الذي يعرض بصيغته تسمع بتعيين مداه

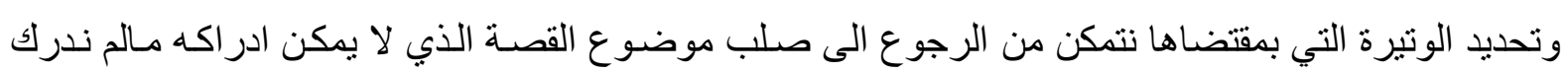

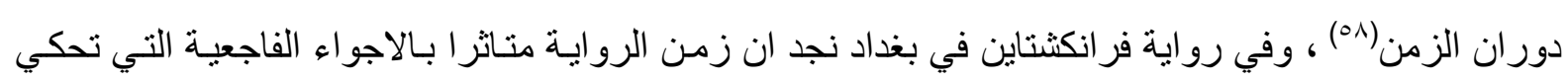

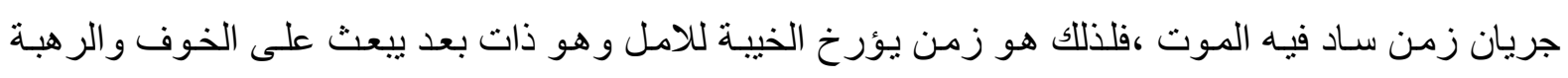

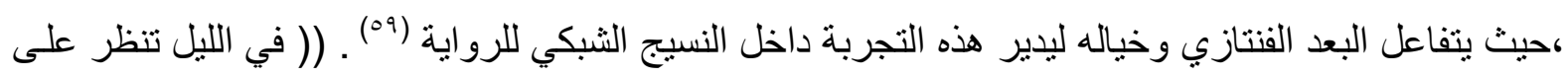
ضوء الفانوس النفطي فترى تموجات الصورة العتيقة خلف الزجاج الثاجب تسمع نابو يموء بضجر وهو يغادر

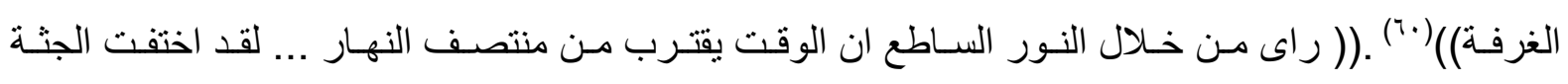

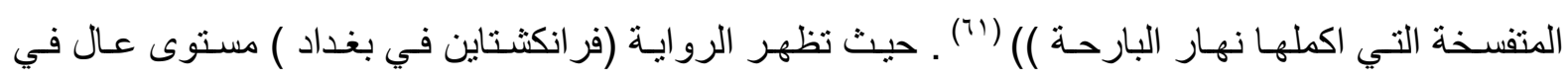

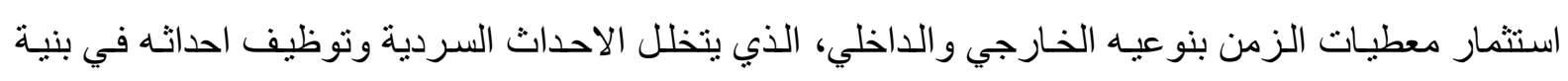
جمالية تحاول محاكاة الواقع ، فالزمن الخـارجي هو الزمن الذي يبقى عند طرفي الرواية أي البدايـة والنهايـة وهو التوقيت القياسـي للاحداث التي تجري الان ويكون هذا الزمن اطسار الخارجيـا (rآ) ، ومـن خـلال ادخـال معطيات الاجتماعية لنقبس عبر ها مسار ات الزمن الخارجي نجد ان الوان هذا الزمن الروائي يمكن ان نسميه

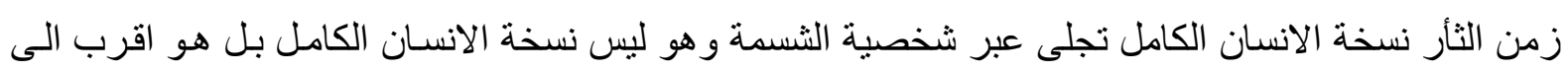

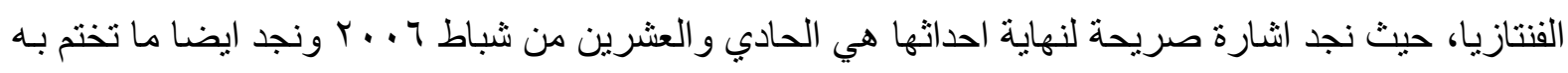

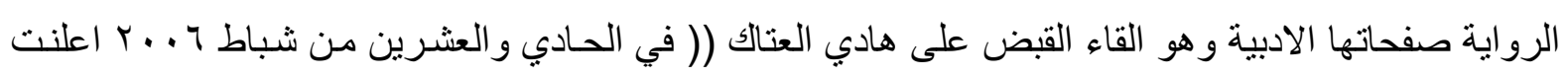
القيادات الامنة العليا في بغداد عن القاء القبض اخير ا على المجرم الخطير .... انـه المجرم هـادي حساني عبد فيد

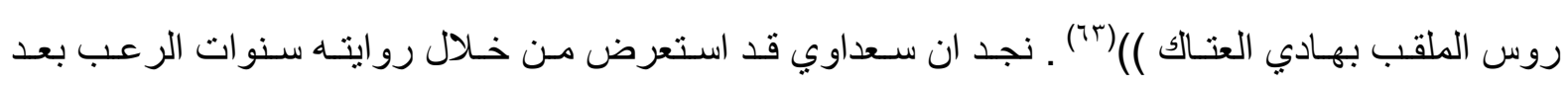
الاحتلال، الامر الذي فرض على الكاتب الدخول عبر خليط مذهل مزج بين الواقعية والفتنازيا مستعينا بمفردات

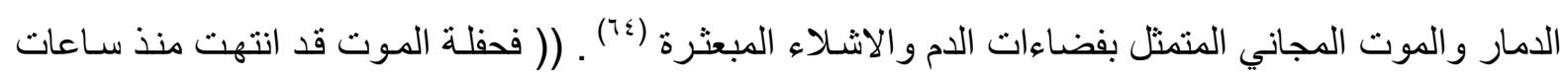
طويلة لكن اثار ها ظلت و اضحة للعيان ربما هو اقوى انفجار يحصل ... شـاهد بقع الدن وبقايـا من فروة راس

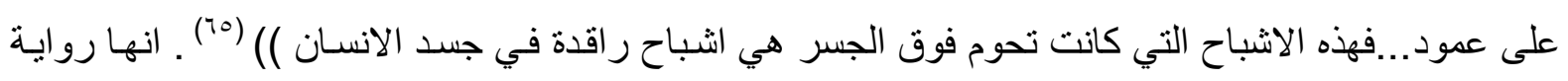
تمتص احداثها اليومية و الاجتماعية من الواقع المعيش، حيث ساد العنف و الرعب و المشـاهد الفنتازيـة من خـلال

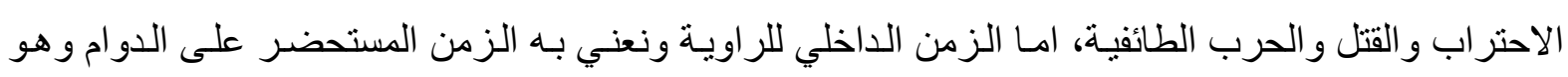

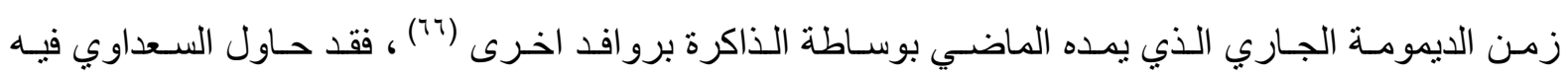

\section{$-V \varepsilon$ -}


الاقتر اب من زمن الموت والجدب والانهيار الثقافي حيث يبدو الزمن متاثر ا بـالاجواء الفاجعيـة التي تحكي جريان زمن ساد فيه الموت و الانفجار ات وتتو الى المشاهد التي تؤرخ لزمن الموت و والخوف حيث نلمحها لدى

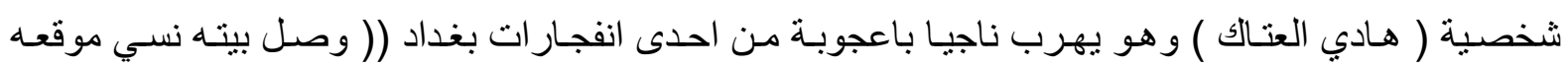

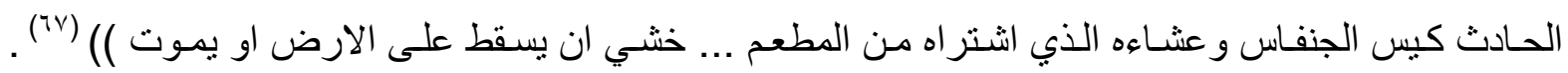
ويضع الباحثون مقياسا اخر لايقاع الزمن الداخلي للرواية هو الزمن النفسي الذي هو زمن نسبي داخلي يقدر

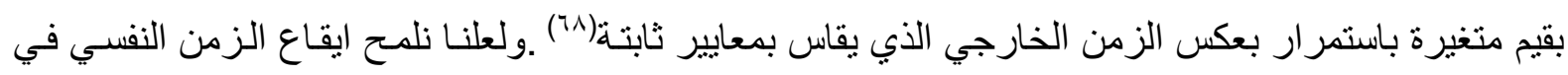

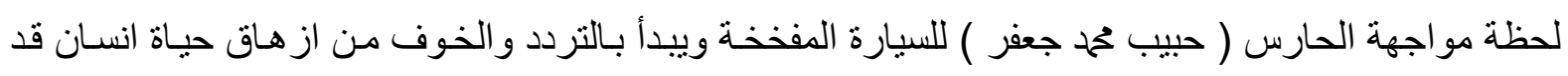
يكون اقتحامة بسيارته الفندق خطأ بشرياً . (( كان حبيب ينظر الى سيار ات النفايات وتتلاحق في ذهنه الاوامر

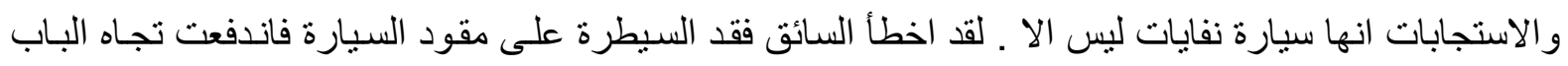

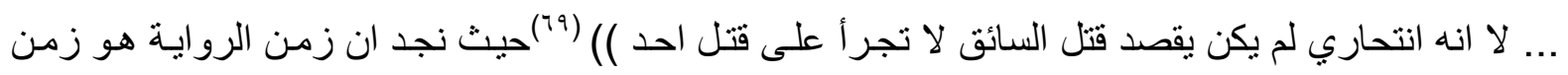
الموت و الفنتازيا و البعد الغر ائبي، حيث تبحث الروح ( الثسمة ) عن الانتقام تلك الرغبة التي تنطفأ معها رغبـة

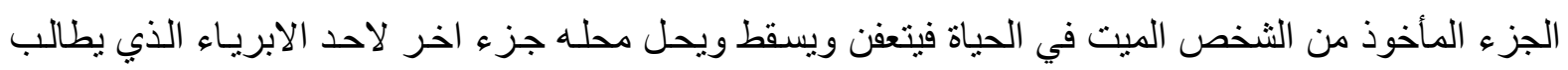
بدوره بالاتتقام من القاتل وهكذا تستمر دوامة العنف و القتل والخوف و الرعب .(( ان اللحم الميت الذي يتكون جسده منه يتساقط من تلقاء نفسه في حالة لم يجر الثأر لصاحبه في الوقت المعلوم كما ان الثأر يصـاحب جذاذة

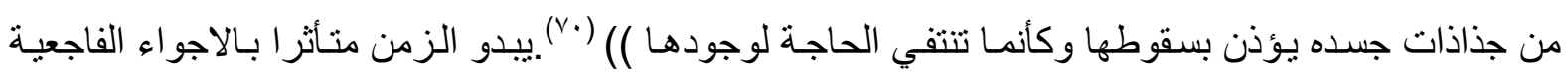
التي تحكي جريان زمن ساد في الموت.

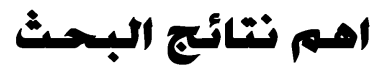

اـتأرجح مفهوم الرعب بين مصطلحات مختلفة، من أهمها: الفنتاستيك، الفنتازيا، الأدب الاستيهامي، الغرائبي،

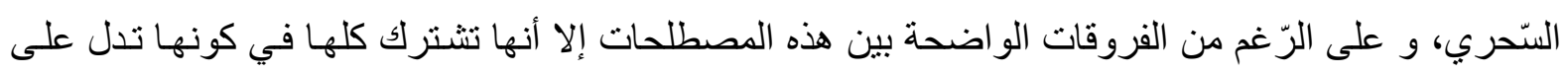
الخارق و اللامألوف و العجيب.

ك-إنّ مقاربة الجانب الفتتازي في رواية "فر انكثتاين في بغداد، أفرز جملـة من النتّائج الهامّة، تتمثل في كون هذا الرعب والجانب الفنتازي قد تحوّل في الرّوايـة إلى بنيـة كلية عملت على الاستيلاء على بـاقي مكونـات

$$
\text { الحكي و توجيهها، و قد برزت فاعليته في البناء الرّوائي العام. }
$$

بـأنّ الأحداث و الثّّحصيات و المكان و الزّمـان كلّها امتلئت بالفنتازيـة، و ذلك لإبراز صفات و تناقضـات الحياة التي تمتلىء بالدم و القتل و التفجير.

عـ- يتجلى من خلال هذه الدّر اسة أنّ الرعب هاجس فني يخترق الو اقع اللامعقول بفن لا معقول، فكانت مهمّة

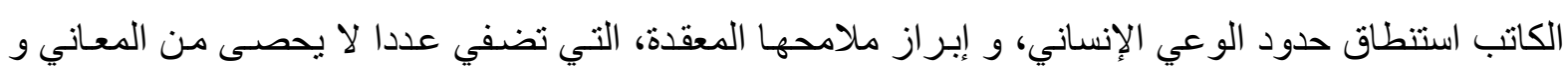


هـ إنّ روايـة فر انكشتاين في بغداد" تتـاخل فيها مو اقف حياتيـة كثيرة، تغوص بالتناقضـات و الصّر اعات، بأسلوب تضمّن الكثير من المجاز و الصور البلاغية، و التي زادتها جمالا و رونقا، و من جهة أخرى استثمار الكثير من النّصوص التراثية و الحديثة التي تتناص معها الرّواية في مواضيع و نقاط مهمة. ج-ان رواية فر انكثتاين انها الرؤية الفنتازية الر امية تبرز مجددا في جو تسود فيهه لغة الدم والقتل من يهوى القاتل قتله هكذا في الظلام وفي وضع النهار تمتد يد الموت لتخطف من تشتاء V-لقد كانت الرّواية فضحاو كثفا للواقع و مساوئه بطريقة عجيبة و غير مباشـرة، تضمنت الكثير من الأمور العجيبة و الخارقة، و كانت العجائبية فيها بديلا عن الكثير من المواقف، حيث يبرز فيها التأويل كعنصر مهّم يجعل القارئ حائر او مترددا دائما. ^- و الرعب اقدم واقوى عاطفة بشرية المتمثل بالخوف و الخوف بكل انو اعه ييقى هاجسا مثير ا خلفه المجهول 9ـ لقد سـاهمت العو امـل السياسـة و الواقع التـاريخي في ظهور ادب الرعب و إثرائها، فحاولت التعبير عن ظو اهره بطرق مختلفة و منتو عة، استتدت إلى المفارقة و السخرية و التحول و المسخ و غير ذلك. • ا ـان ادب الرعب في العراق يكاد يكون قليلا ان لم يكن معدوما قياسا بالمستوى العالمي او العربي فرواية السعداوي تعد رواية رعب واضحة في ملامحها بالر غم من وجود محاو لات سـابقة لمشـاهد رعب ليس كاعمال كاملة تجسد هذا التوجه الـان الاهتمـام بـادب الرعب في السـاحة الفنيـة العر اقيـة لا يرقي الـى مستوى الطموح سـواء على مستوى الانتاج الادبي او الدراسة النقدية

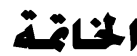

رو اية فر انكشتاين في بغداد قد عالجت واقعا معاثـا في العر اق بطريقـة فتنازيـة غر ائبيـة ممـا يسمح لنـا باعادة تاكيد وتصنيفها ضمن الواقعية الغرائبية حيث نسج احمد سعداوي شخصية فنتازية مر عبة حيث تظهر هذه الثخصية الفتنازية وسط غابة العبث لجثت متساقطة كل يوم بشتى الوسائل ابسطها وابرز هـا تفخيخ الجسد

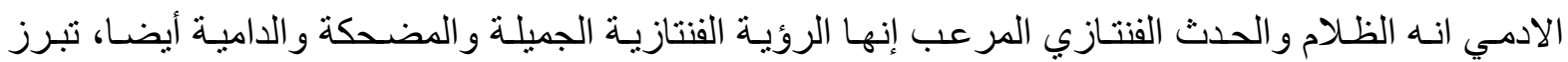
مجدداً، في جو تسود فيه لغة الدم والكاتم وتفجير الأماكن العامة وقتل من يهوى القاتل قتله، هكذا في الظلام أو لو في وضح النهار تمتد يد الموت لتختطف من تشاء وتريد، وهي قادرة على المطاولة والتهديد و الفعل في منـاخ موتور من البغضاء و الثحناء والإقصاء المنبادل بين اطياف المجتمع العر اقي شخصيات عديدة تمر في الروايـة

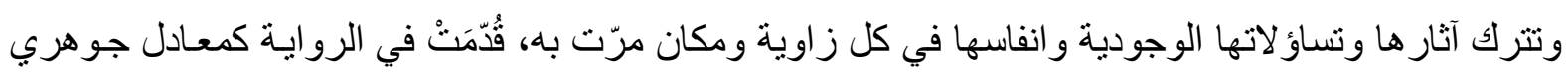
لثعب كامل، شخصيات لها هو اجسها وطموحاتها، ومشاغلها و همومها اليومية. إنها در اسـة سـايكولوجية معدقة للثخصيات، وصورة بانور امية جامعة، أخاذة، تلك التي رسمها سعداوي لشخصياته الحيوية والفاعلة على طول صفحات الرواية،، ومن هذه الشخصيات فرج الدلال، محمود الصحفي، بـاهر السعيدي، هـادي العتاك، العميد

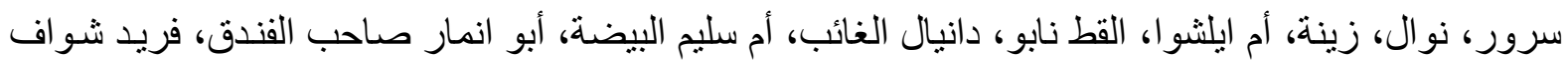


مصمم المجلة، المصور حازم عبود، أبو سليم الجالس في شرفته ير اقب حركات المـارة في الثـارع، وعزيز المصري صاحب المقهى الذي يسرد عليه هادي العتاك يتناول هذا البحث رواية جعلت ميدانها حقبة زمنية غايـة

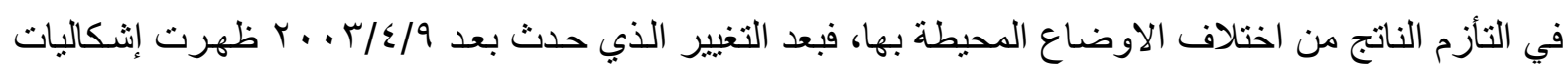
اجتماعية متتو عة، واستطاعت القوى والتيار ات والفعاليات الاجتماعية التي كانت مكبونةً أن تتنفس وأن تعرض فئ قيمها ورؤاها التي كان من الطبيعي أن تصب باتجاهـات متغايرة نتيجة لعدم الاتسـاق في رؤيسة واحدة ، و وعدم الاتفاق على مشروع وطني جامع، ومن هنا نستطيع تفسير التداعيات الكبيرة التي أصبحت نتائجها كارثية على فيلى الفرد العر اقي. ولقد حاولت رواية (فرانكثتاين في بغداد) الاقتراب من زمن الموت ومنئ والجدب والانهيـار الثقافي للمجتمع ، عن طريق محاكاة تقترب من الواقع، حيث قامت بتوظيف عناصـره الأولية في صياغة خطابها التخييلي، وقد حاولنا ملاحقة ايقاع الزمن ودوره في بنـاء شخصيات الرواية ببعديـه الخـارجي المشكل لإطـار

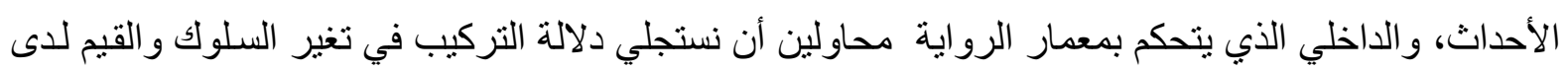

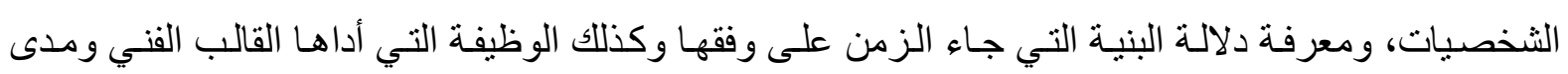
نجاحاتها .

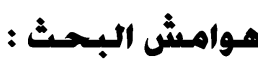

'ـ احمد سعداوي يلملم انشلاء فر انكشتاين في بغداد ، عبد الجبار العتابي ايلاف ، اول جريدة بومية الكترونية من لندن المايو

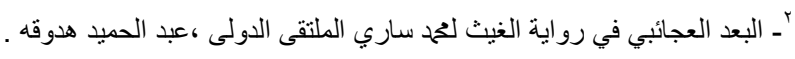

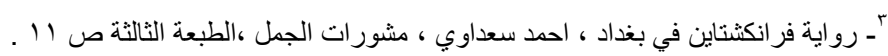

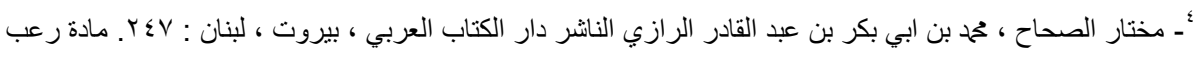

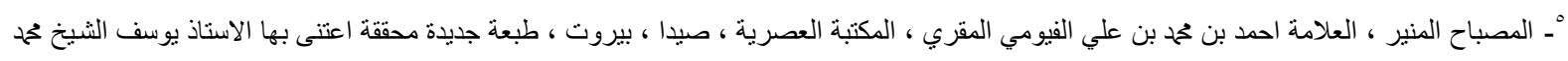

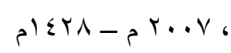

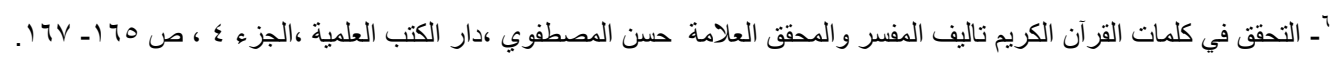

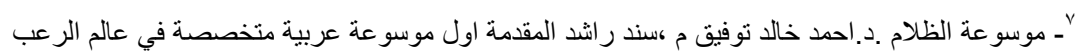

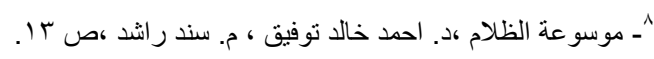

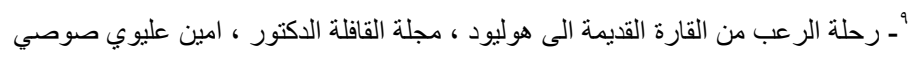

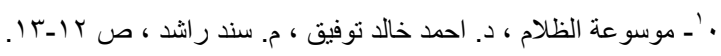

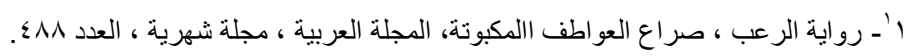

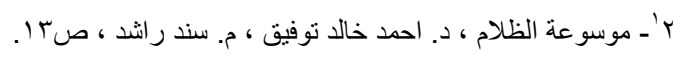

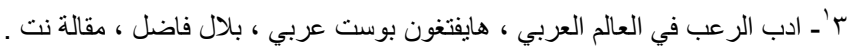

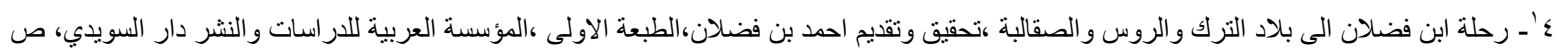
$97-90$

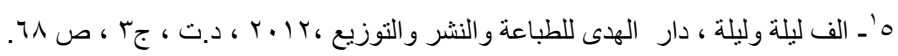

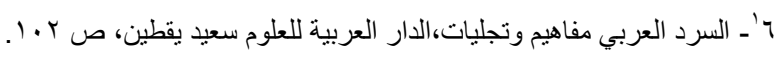

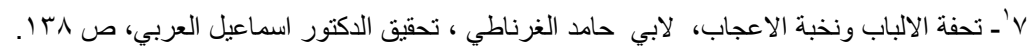

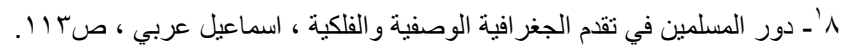

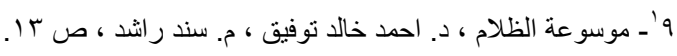

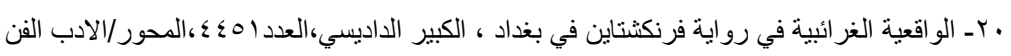

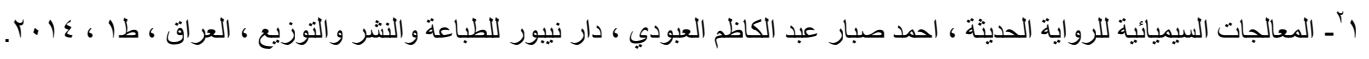

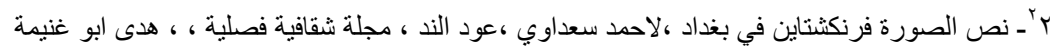

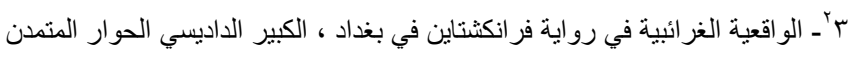




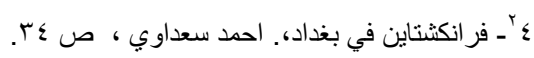

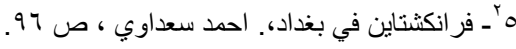

( (T) Harrey . Sir Paulced the Oxford compani to English literature fourth edition oxford . great Britain . 197V,p. YMY.

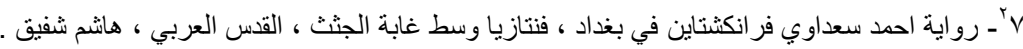

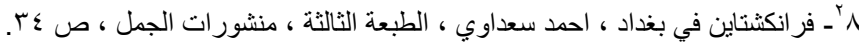

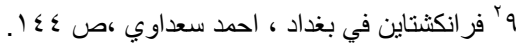

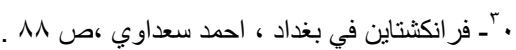

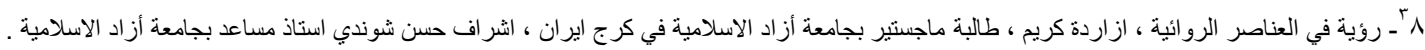

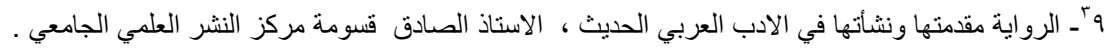

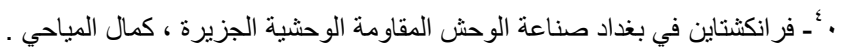

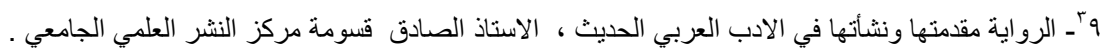

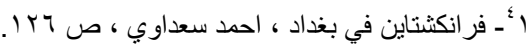

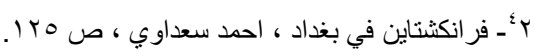

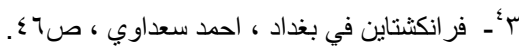

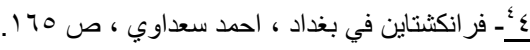

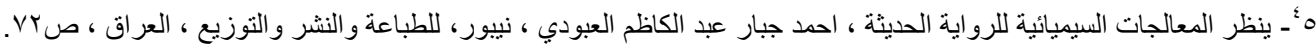

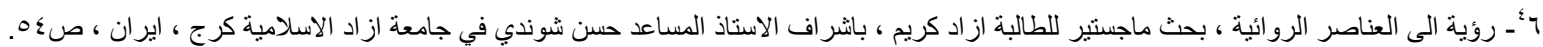

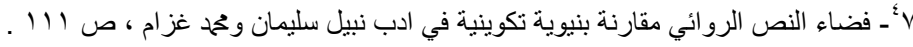

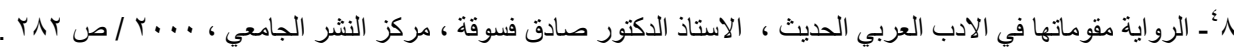

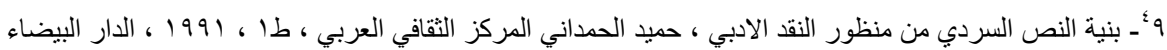

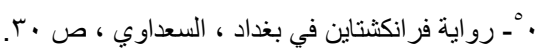

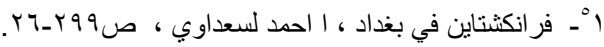

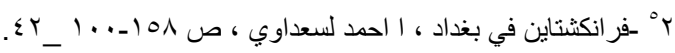

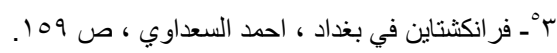

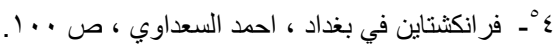

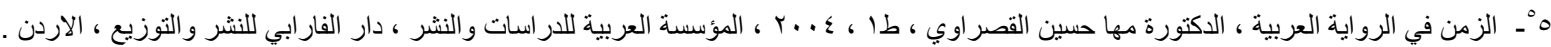

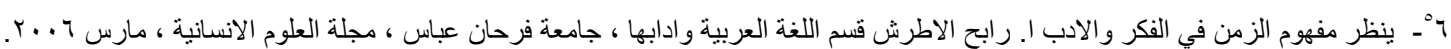

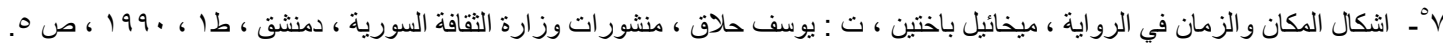

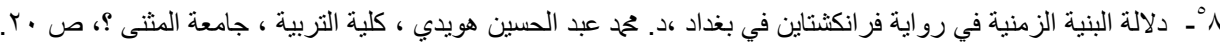

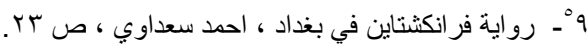

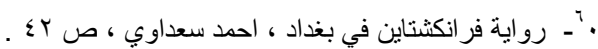

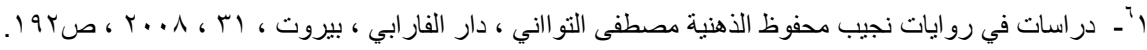

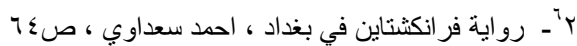

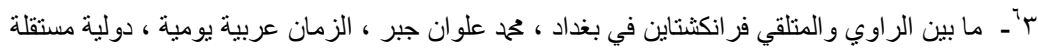

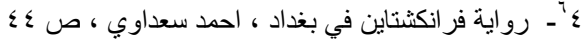

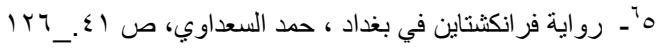




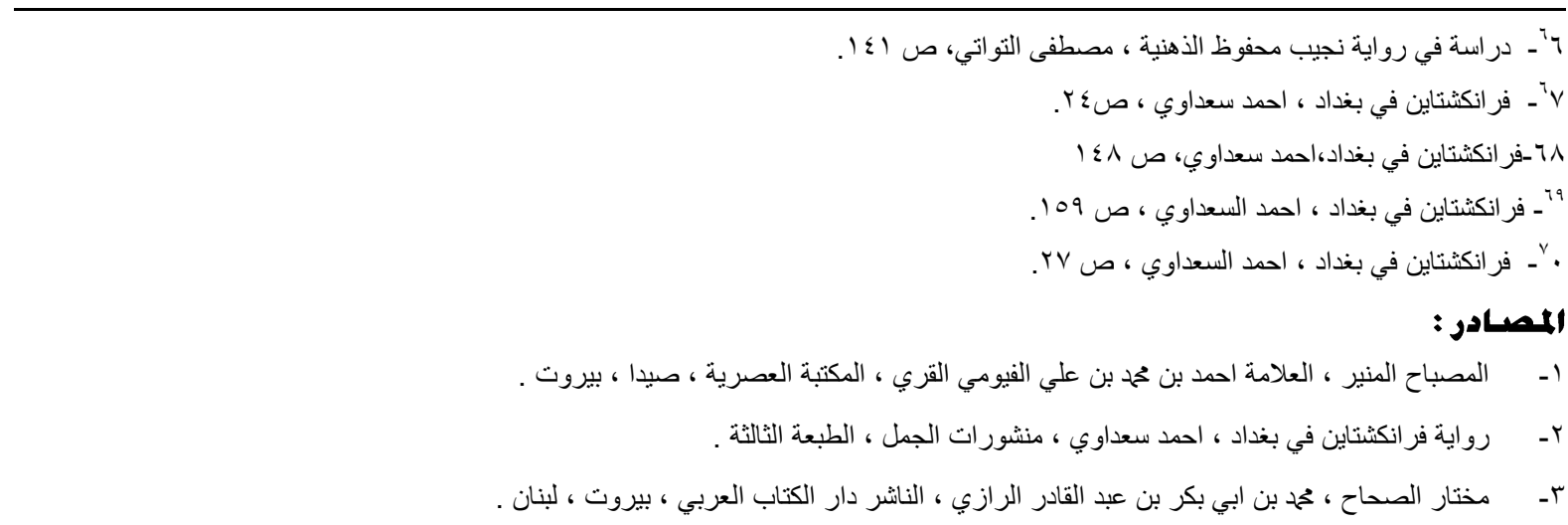

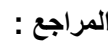

1- اشكال المكان و الزمان في الرواية ميخائيل ياختين ، تقديم : يوسف حلاق ، منشورات وزارة الثقافة السورية ، دمشق ، ط1 ، .199 ـ

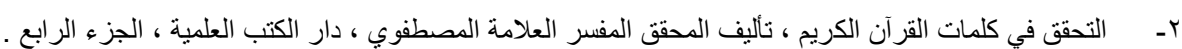

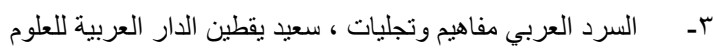
ع - الزمن في الرواية العربية ، الدكتورة مها حسين القصراوي ، طع ، ع . . ب ، المؤسة العربية للدراسات و الثر الفارابي للنشر و التوزيع ، الاردن

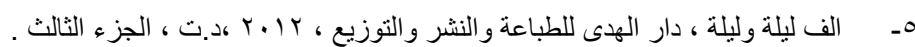

ד- بنية النص السردي من منظور النقد الادبي ، حميد لحمداني ، المركز الثقافي العربي ، طا ، 1999 ، الدار البيضاء.

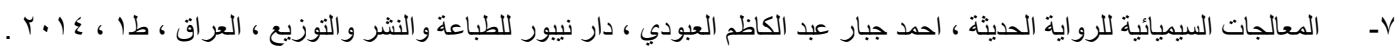
ي- تحفة الالباب ونخبة الاعجاب تصنيف لابي حامد الغرناطي ، تحقيق الدكتور اسماعيل العربي . 9- دراسات في روايات نجيب محفوظ الذهنية مصطفى التو اتي ، دار الفار ابي ، بيروت .

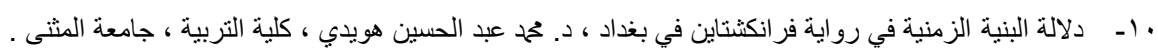

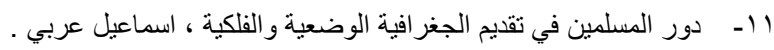

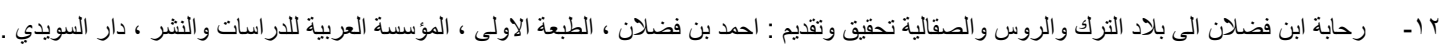

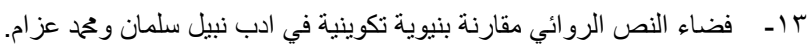

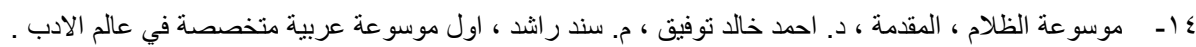

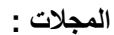

1- احمد سعداي يلملم اشلاء فر انكثتاين في بغداد ، عبد الجبار العتابي ، ايلاف ، اول جريدة يومية الكترونية .

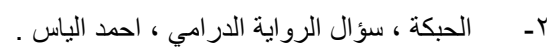

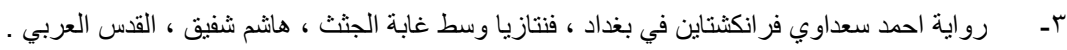

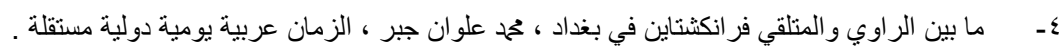

ا - رؤية في العناصر الرو ائية . أز ادة كريم طالبة ماجستير بجامعة أز اد الاسلامية في كرج ايران ، اثر اف حسن شوندي استاذ مساعد بجامعة از اد الاسلامية .

www. Huff poctarabi . com

$$
\text { ا- ادب الرعب في العالم العربي ، هايفغتون بوست عربي مقالة نت }
$$

$$
\begin{aligned}
& \text { r- الرواية مقوماتها في الادب العربي الحديث الاستاذ الدكتور الصادق فسومة ، مركز النشر الجامعي . }
\end{aligned}
$$

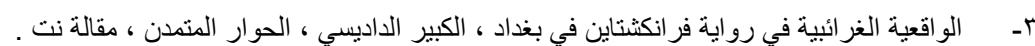

www. Mahawar . org . debet www. Aljazeera . Net . 